\title{
Reference dependence, loss aversion and residential property development decisions
}

\author{
Helen X. H. Bao ${ }^{1}$. Charlotte Chunming Meng ${ }^{1}$ (D) . Jing $\mathrm{Wu}^{2}$
}

Received: 26 February 2020 / Accepted: 7 December 2020 / Published online: 3 February 2021

(c) The Author(s) 2021

\begin{abstract}
We analyse land transaction and residential development data from Beijing, China and identify that developers' evaluation of land transaction exhibits reference dependence and loss aversion. Developers with prior land transaction losses set higher house prices than those without prior losses. This effect is strongest at the beginning and towards the end of the property sales period. It is moderated by developers' ownership structure and listing status. Privately-owned firms experience stronger effects than their state-owned counterparts, whereas unlisted firms are more strongly affected than their listed counterparts. Results have implications on the relationship between the land and the housing markets in China. In a booming land market where land acquisition entails a high price, developers will transfer excess land price to house prices, thereby increasing the latter. The land market plays an integral role in managing housing prices in China.
\end{abstract}

Keywords Reference dependence $\cdot$ Loss aversion $\cdot$ Behavioural economics $\cdot$ Real estate development $\cdot$ Chinese housing market

\section{Introduction}

Hedonic price models are routinely used to price residential properties. In such models, the pricing decision is assumed rational, and they only consider attributes that add value to properties. However, extant literature identified numerous behavioural factors influencing house markets, such as anchoring (Bokhari and Geltner 2011; Liu et al. 2015), inattention (Kleven and Waseem 2013; Pope and Schweitzer 2011), risk salience (Fekrazad 2019) and loss aversion (Anenberg 2011; Bokhari and Geltner 2011; Genesove and Mayer 2001).

Charlotte Chunming Meng

cm794@cam.ac.uk

Helen X. H. Bao

hxb20@cam.ac.uk

Jing Wu

ireswujing@tsinghua.edu.cn

1 Department of Land Economy, University of Cambridge, Cambridge CB3 9EP, UK

2 Hang Lung Center for Real Estate, Tsinghua University, Beijing 100084, China 
Although these studies vary greatly in terms of geographic regions and behavioural factors, they have reached two consensuses: the inclusion of behavioural factors significantly enhances the performance of hedonic price models, and prospect theory is the most widely used and applicable behavioural model in this stream of research (see, for example, Barberis 2013; Engelhardt 2003; Genesove and Mayer 2001). In this paper, we push the boundary of behavioural research in real estate studies along these directions.

We focus on the behavioural factors of reference dependence and loss aversion, two well-documented concepts from prospect theory (Kahneman and Tversky 1979; Tversky and Kahneman 1992). Reference dependence refers to people's tendency of deriving utility from a comparison with a reference point; loss aversion refers to people's tendency of stronger reaction to losses than to equal-sized gains. ${ }^{1}$ In the real estate market, the two concepts are helpful in explaining market cycles (Anenberg 2011; Bokhari and Geltner 2011; Genesove and Mayer 2001), household mobility decisions (Engelhardt 2003), REITs performance (Bao and Gong 2016) and mortgage lender and borrower's behaviour (Ong et al. 2008, 2007), amongst others. However, most of the existing studies investigate individual or household decisions. Little is known if other market participants, such as real estate developers, are prone to such biases.

A typical residential property development project starts with real estate developers buying a plot of land and ends with them selling the properties developed on the plot. If developers price the properties rationally, then they would consider only the market value of the attributes in hedonic price model at the time of sales. Hence, land acquisition cost is irrelevant sunk cost. However, evidence from behaviour economics corroborates that people are likely to evaluate consecutive events together if they experience prior losses in the first event, in the hope of breakeven (Barberis and Huang 2001; Thaler and Johnson 1990). If real estate developers are also affected by loss aversion due to previous land acquisition losses, then they are likely to pursue breakeven by setting the asking prices of their housing units above the fair market prices. The study of such behaviours are of economic and policy importance. Developers may want to pursue project-specific breakeven as much as they could. However, this is very difficult to achieve in competitive and volatile market conditions, and firm-level breakeven strategy should be adopted. Thus, the sunk cost of a specific project, i.e. losses due to excessive payment for a plot of land, should be written off and ideally offset by profits from other projects. This behaviour is closely related to myopic loss aversion and narrow framing in the behavioural literature, and the adverse impacts of such behaviours are well documented (Benartzi and Thaler 1995). Secondly-and more importantly-loss aversion leads to disposition effect and, subsequently, long time-on-market and potentially high final transaction prices (Barberis and Xiong 2009; Odean 1998; Shefrin and Statman 1985). In the real estate development context, any pricing mistake (e.g. overpaying for a plot of land) is not corrected fully and timely in the subsequent sales of complete housing units. Therefore, policymakers should be wary of any loss aversion effect resulting from the land acquisition stage. Housing price regulations would most probably be effective if policies target the source of the issues, such as the overpricing of land.

We choose Beijing, China as our study area because it offers an ideal setting to test our hypotheses. The state owns all urban lands in China. Real estate developers can only obtain the right to use residential lands through public auctions of land leases from local

\footnotetext{
1 Evidence from various fields has confirmed the key roles of reference dependence and loss aversion in human decision-making processes. For an excellent review about the applications, see (Barberis 2013).
} 
governments. This institutional setting offers two benefits to our analysis. Firstly, land prices are transparent and recorded accurately through the public auction platforms. Secondly, the limited supply of land parcels and the fierce competition in public auctions make it possible for developers to overbid, and consequently incur sizable losses in later stages of the development process. The highly supply-constrained market environment also allows loss aversion to demonstrate its effect. These features facilitate the reliable identification of loss aversion effect due to land transaction losses.

We analyse land and house transaction records from 2003 to 2014 and find that real estate developers' pricing decisions for newly built properties exhibit reference dependence and loss aversion. When they pay prices higher than the reference land prices, they tend to set $14 \%$ higher house prices than developers without such losses. Loss from land acquisition transactions strongly affects developers' pricing behaviour in the first year of the sales period. ${ }^{2}$ However, developers become rational as sales progresses into the second and the third year and when additional market information is taken in. The loss aversion effect is lowest at the third year of sales period, which is the average time to sell out housing units within a project in our sample. Our findings also confirm previous conclusions on disposition effect. We contend that the most loss-averse developers took the longest time to sell out their properties, i.e. eight years in our sample. These findings not only add to the fastgrowing behavioural literature in real estate research but also highlight the important role of land market in China's housing market.

The rest of this paper is organised as follows. A description of the theoretical framework is presented in Sect. 2, whereas the background information about real estate development in China is provided in Sect. 3. The details of our empirical implementations are described in Sect. 4, followed by the presentation of empirical results and several robustness checks in Sects. 5 and 6, respectively. Conclusions and proposals for future research directions are provided in Sect. 7.

\section{Theoretical framework}

We develop our empirical models based on prospect theory(Kahneman and Tversky 1979), which has been applied in a wide range of fields such as finance (Benartzi and Thaler 1995; Odean 1998), marketing (Bronnenberg and Wathieu 1996; Hardie et al. 1993; Putler 1992; Ray et al. 2015) and real estate economics (Anenberg 2011; Bokhari and Geltner 2011; Engelhardt 2003; Genesove and Mayer 2001), amongst others. ${ }^{3}$ The introduction of reference dependence and loss aversion is the most significant improvement that prospect theory offers to the standard economic literature. Reference dependence means that decision makers asses the value of a bundle of goods or services relative to a reference point rather than their absolute values. Loss aversion is the tendency of disliking losses more than favouring equal-sized gains. In the current study, we focus on these two elements, as illustrated in the following formula:

\footnotetext{
${ }^{2}$ Sales period starts from the year when the project started to sell its units to the year when all of the units in the project were sold. Presales are not considered all sales in our database after construction was completed.

${ }^{3}$ For a comprehensive review on this stream of literature, see Barberis (2013) and DellaVigna (2009).
} 


$$
v(x)=\left\{\begin{array}{l}
(x-r e f)^{\alpha}, x \geq r e f \\
\lambda(r e f-x)^{\beta}, x<r e f
\end{array}\right.
$$

where $x$ is the bundle of goods/services consumed; ref is the reference point; $\alpha$ and $\beta$ take positive values between 0 and 1 ; and $\lambda$ is the coefficient that measures the degree of loss aversion.

In the context of real estate development, prospect theory predicts that the reference points of real estate developers will affect their pricing decision. Moreover, their behaviours will be affected by loss aversion. Developers evaluate the outcome of land auctions by comparing transaction prices with reference prices (e.g. their expectation). This comparison will put the developer in either a gain domain if the transaction price is greater than the expectation, or a loss domain if the transaction price is less than the expectation. Prospect theory then predicts that developers' behaviours are different in the two domains. Decision-makers tend to be risk seekers in the loss domain and risk aversive in the gain domain.

The concept of reference dependence is also related to a long-standing idea in the psychology literature. This idea states that prior outcomes will affect people's decision-making afterwards. In principle, prior costs are sunk costs that are not recoverable. Therefore, future decision-making should not involve them. However, empirical evidence shows that decision-makers are influenced by sunk costs (Arkes and Ayton 1999; Arkes and Blumer 1985). Behavioural economists further expand the idea of sunk costs to sunk losses and gains (for simplicity, we term both as prior outcomes hereafter). They also use prospect theory to explore the effect of prior outcomes. In the well-known study of Thaler and Johnson (1990), lab experiment evidence is obtained to show that people increase their riskseeking behaviour after a prior gain (house money effect) and tend to pursue breakeven after prior loss. Thaler and Johnson explained the results with quasi-hedonic editing rules. They argued that peole tend to segregate the prior gain from subsequent gains but integrate the gain with subsequent losses (cancel-out). By contrast, they tend to integrate prior loss with subsequent gains (cancel-out) but segregate it from subsequent losses. People follow these rules to reduce pain from the loss. Inspired by this paper, Barberis et al. (2001) defined loss aversion behaviour with the influence of prior outcomes. According to them, people are less loss averse after prior gain because the gain provides cushion for subsequent losses. Moreover, they experience increased loss averse after a prior loss because the loss heightens their sensitivity to subsequent losses.

This conclusion leads us to another concept for understanding prior loss effect: mental accounting (Shefrin and Statman 1985; Thaler 1985). The term refers to people's cognitive process to think about, evaluate and organise economic outcomes. Therefore, when land transaction takes place, the developer opens a mental account to evaluate the transaction. In the following stage when developers set house prices, they might close the account for land transaction and open a new account for house sales, or they might integrate the two process and evaluate the two transactions in one integrated account. If developers use segregate accounts, then land transaction outcomes should not affect developers' asking price for houses. However, in the presence of integrated account, setting a high house prices would offer developers in the loss domain a chance to breakeven and reduce negative feelings from the land transaction (Thaler and Johnson 1990). According to prospect theory, real estate developers are likely to use integrated account, especially in the loss domain. Losses from previous land transactions (paper/unrealised costs) will be considered in the 
pricing decisions of housing units. Therefore, their pricing decision can be described by the following formula:

$$
P_{i t}=\alpha_{0}+\boldsymbol{X}_{i} \boldsymbol{\beta}+\delta_{t}+f\left(\operatorname{loss}_{i}\right)
$$

where $P_{i t}$ is the house price for properties on land lot $i ; X_{i}=\left(x_{1}, x_{2}, \ldots\right)^{\prime}$ is a matrix of observable property attributes; $\delta_{t}$ represents the time fixed effect; and $\alpha_{0}$ is a constant; $\operatorname{loss}_{i}$ is the truncated differences between land transaction prices and developer's reference points, as defined in Eq. (3).

$$
\text { Loss }_{i}=\left(\text { Refrerencepoint }_{i}-\text { Landprice }_{i}\right) \times D\left(\text { Referencepoint }_{i}<\text { Landprice }_{i}\right)
$$

where $\mathrm{D}($.$) is a function that is equal to 1$ when the condition in the bracket holds, and 0 otherwise.

A typical hedonic price model includes the first three components in Eq. (2). The underlying assumption is that developers consider only the 'house account' when pricing housing units. When developers integrate 'house account' and 'land account', the gain/loss measure also enters the hedonic price model, as given in Eq. (2). According to prospect theory and mental accounting, the losses and gains from land transactions affect real estate developers' behaviours differently. If developers are in the gain domain (i.e. land acquisition costs are below their expectations), then they will behave rationally when determining the asking price of housing units completed on that plot. However, if land price is above their reference point, then they will suffer from loss aversion. They will also subsequently set high asking prices for new homes built on the land lot in the hope of breaking even. In summary, standard economic theory predicts that $f\left(\operatorname{loss}_{i}\right)=0$, whereas prospect theory predicts that $f\left(\operatorname{loss}_{i}\right)>0$. We use data from China to test these hypotheses in the succeeding parts of the study.

\section{The land market and real estate development in China}

Before the 1990s, employers provided free housing for urban residents in China. All lands are owned by the state. Hence, a market for land transactions did not exist, and real estate development by private companies or individuals was impossible. In the mid-1980s, land reform successfully implemented the leasehold property right system in China. Under the new system, the government still owns all urban lands, but land use right can be leased to individuals or institutions. In the early 1990s, most lands were leased through private negotiation between the local governments and the buyers, which gave rise to corruption and led to unfair (often at lower prices) transactions. Since 2002, the government has mandated that all land transactions must be conducted publicly and transparently through auctions, tenders or listings. Consequently, information regarding land transactions between local governments and developers is publicly available at government websites in real time nowadays.

During the same period of time, China also underwent another important reform-the tax-sharing reform or fiscal decentralisation. The 1994 fiscal tax-sharing reform reduced the share of local government in tax revenues significantly. Consequently, local governments turned to land leasing income to relieve fiscal distress (He et al. 2016). Land leasing revenue makes up over 50\% of local government fiscal income between 2000 and 2018, 

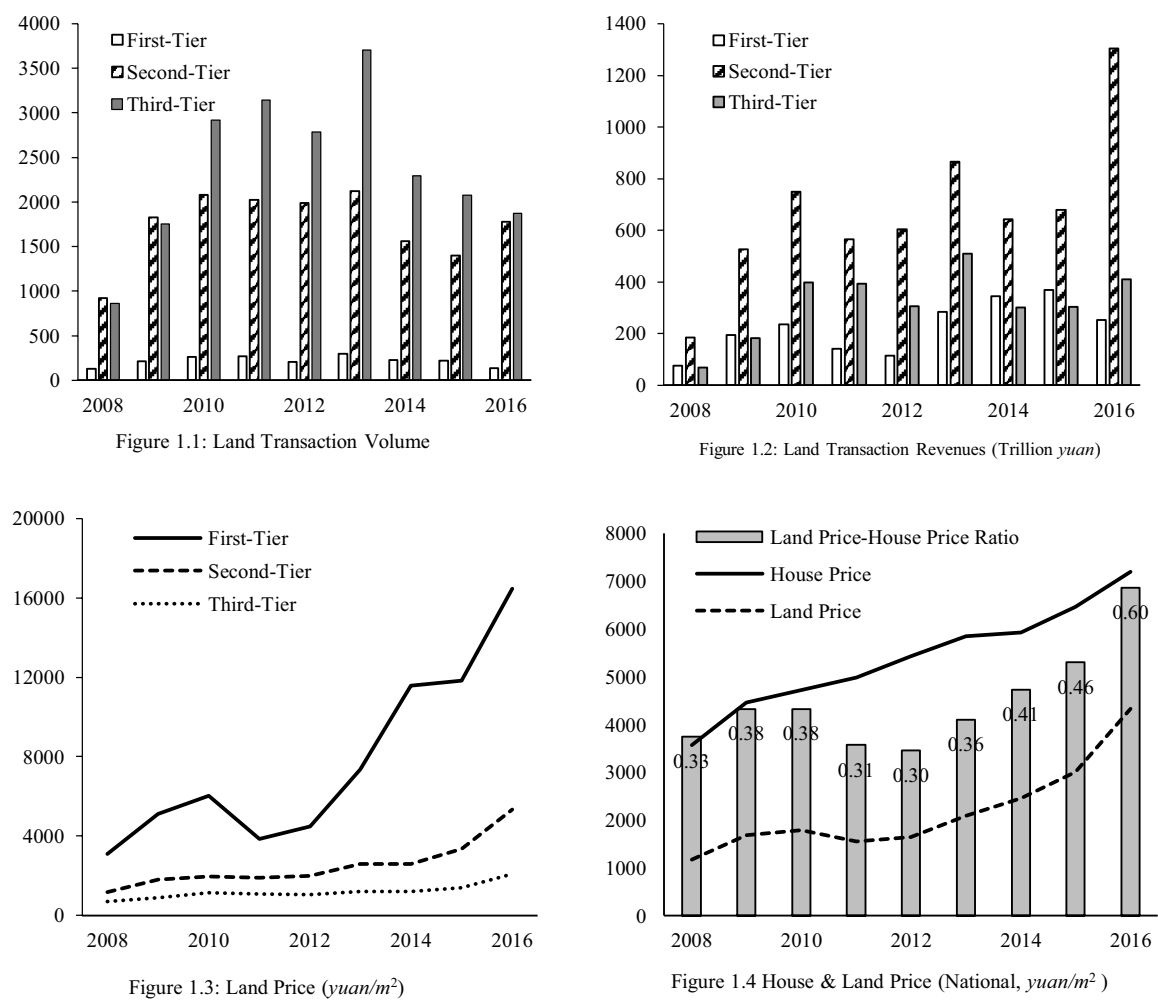

Figure 1.4 House \& Land Price (National, yuan $/ \mathrm{m}^{2}$ )
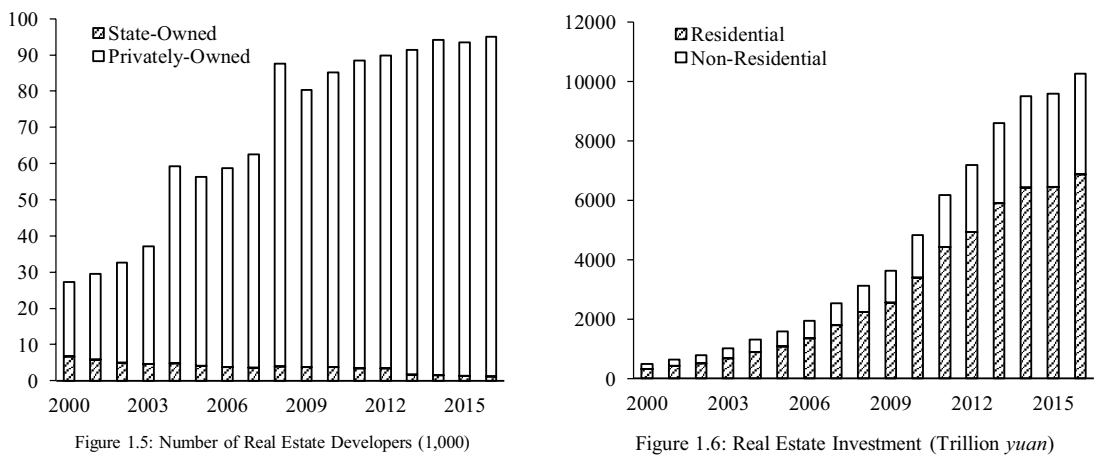

Sources: Wind \& National Bureau of Statistics of China

Fig. 1 Real estate development in China. Sources Wind and National Bureau of Statistics of China

according to the Ministry of Finance, China. Local governments rely heavily on land leasing income for public finance. They are motivated to limit the supply of development land in order to boost house and land prices and subsequently their revenue from land leasing (Du and Peiser 2014). As shown in Fig. 1.1 and 1.2, the transaction volume and revenues from land use right transactions have been increasing steadily between 2008 and 2016. 
Although the local governments of third-tier cities had leased the largest amount of lands during this period, the revenue from land leasing was lower in comparison to that from second-tier cities. This is due to the low land prices in third-tier cities (see Fig. 1.3). Land transaction volume in first-tier cities remains low not only because most land lots in those cities have been developed already, but also because local governments in these cities are more motivated to limit the supply of development land. The unmet demand in first-tier cities escalated land prices from approximately $3000 \mathrm{yuan} / \mathrm{m}^{2}$ to $17,000 \mathrm{yuan} / \mathrm{m}^{2}$ in less than a decade (see Fig. 1.3). Figure 1.4 shows the national-level house and land prices. Whilst both prices increase consistently, land price has comprised much higher proportion in house prices in recent years. The land market plays an important role in the fast-growing housing market in China. Outcomes from land transactions can substantially influence real estate developers' decisions in the later stages of the real estate development process.

Alongside the land reform was the gradual commercialisation of the housing market in China. Housing provision from the public sector gradually and steadily gave way to a fastexpanding private housing sector. Real estate development projects mushroomed, firstly in coastal cities, and then quickly spread to inland areas. Figure 1.5 demonstrates the significant growth in the number of real estate developers from 2000 to 2008, especially in the private sector. Figure 1.6 shows the rapid growth of real estate investment in the same period, especially in the residential sector.

To develop residential projects, real estate developers need to lease land parcels from local governments, who are the sole providers of residential development land in China. In first tier cities such as Beijing, the competition in land auctions, tenders and listings are fierce, given the large number of developers and limited number of land parcels made available by local governments. Developers bid based on their predictions of future house prices (Wen et al. 2018). However, the significant mismatch of supply and demand inevitably pushed up land prices. It is not uncommon for developers to bid land prices to be above the expected house prices of nearby sites. Under this circumstance, it is possible for the successful bidder to suffer a loss if future house prices are not high enough to cover the costs to complete the project.

In an efficient and free land market, if this happens the developer will have to write off the loss and move on. In China's highly regulated land market, however, developers are likely to recover the loss by setting the price of completed units to be above the current market level. There is a feedback loop among land supply from local governments, land prices, and house prices. Specifically, high house prices will encourage local government to reduce land supply in order to push house price further up. Local government's monopoly position leaves developers no choice but to pay high prices to secure land use rights in auctions/tenders/listings. Once developers have secured land use rights, they take the monopoly position as suppliers of housing units in the market. They will set the selling price of housing units as high as possible. Higher house prices will in turn encourage local government to further restrict the supply of land in the next round of land use rights sales. This feedback loop is self-reinforcing, and the result is double- or nearly double-digit house price growth rate for more than a decade in many first-tier cities in China. This trend and momentum encourage buyers to accept the high house prices set by developers, because the expectation is that house prices will keep such a rapidly increasing trend in the foreseeable future.

In summary, efficient market conditions will discourage or even eliminate loss aversion, whist the highly supply-constrained market environment in China leaves room for loss aversion to demonstrate its effect. This is particularly true in Beijing, where land supply is extremely limited and house prices are among the highest in China. Therefore, we choose Beijing as the test ground of our theoretical model. Further details of data from the study area are given in the next section. 

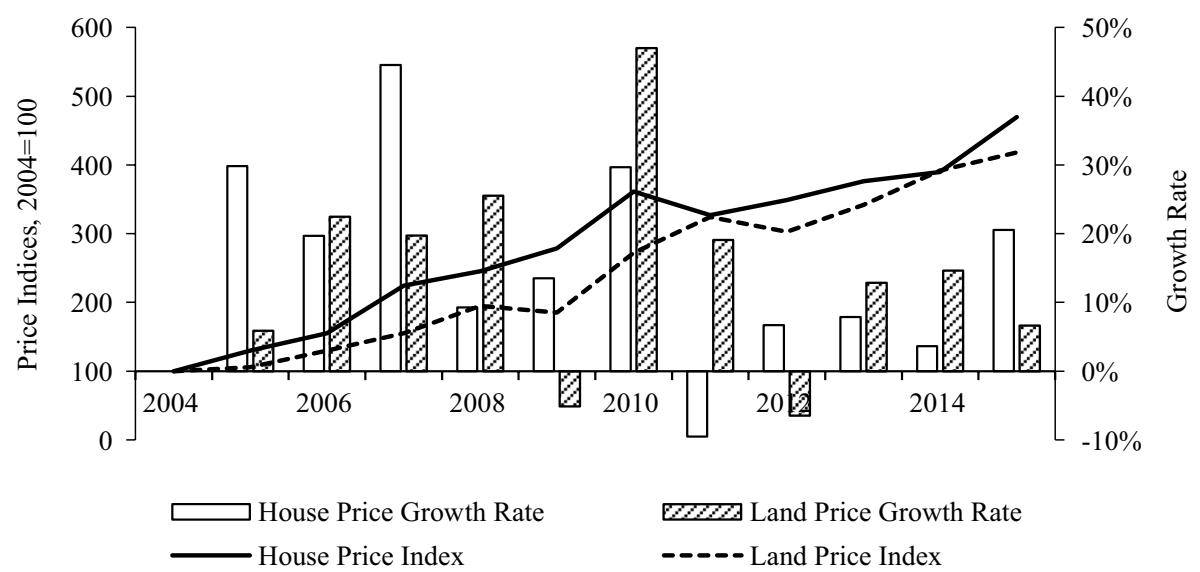

Q\%? Land Price Growth Rate

- - - Land Price Index

Fig. 2 House and land price indices in Beijing (Annual): 2004-2015. The left axis represents indices; the right axis represents growth rates. For both indices (left axis), 2004 $=100$. Sources House price indices are retrieved from National Bureau of Statistics of China. Land price indices are retrieved from Deng et al. (2012). Growth rates (right axis) are from authors' own calculation

\section{Empirical implementations}

\subsection{Data and the study area}

We collect data from Beijing, the capital of China. Beijing has experienced a rapid population growth and sprawled considerably in the last few decades. The number of registered residents jumped from 2.03 million in 1949 to 21.15 million in 2013, whereas the number of unregistered residents increased from 0.06 million in 1949 to 8 million in $2013 .{ }^{4}$ The growing population density pushed the demand for residential property developments. Consequently, land prices and house prices soared rapidly. Figure 2 exhibits the annual residential land and house price indices and their growth rates from 2004 through 2015. House prices maintained high growth rate, except in 2011 when a package of governmental policies to control speculative investment and cool down the market was implemented. ${ }^{5}$ Notably, land price rose as rapidly alongside house price. In six years out of the period examined, the growth rate of land price even exceeded that of house price. As such, land acquisition fee has become a major cost in real estate development. In 2000, land purchase cost accounted for only approximately $15 \%$ of the total investment in real estate development. The number reached $50 \%$ in $2015 .^{6}$

\footnotetext{
${ }^{4}$ Data retrieved from Beijing Municipal Bureau of Statistics (http://www.bjstats.gov.cn). The household registration system, or Hukou in Chinese, is the official system that identifies a person's residency in an area.

${ }^{5}$ The examples of the policies are that, the down payment rate increased from 20 to $30 \%$ for all first-time home buyers; the mortgage rate discount declined from 30 to $15 \%$ of the benchmark interest rate; the same family would have to pay higher down payment and mortgage interest if purchasing second or third properties; mortgage loans to non-residents of a city were suspended unless they could prove that they have had paid taxes in that city for at least one year.

${ }^{6}$ From Beijing Municipal Bureau of Statistics (http://www.bjstats.gov.cn).
} 


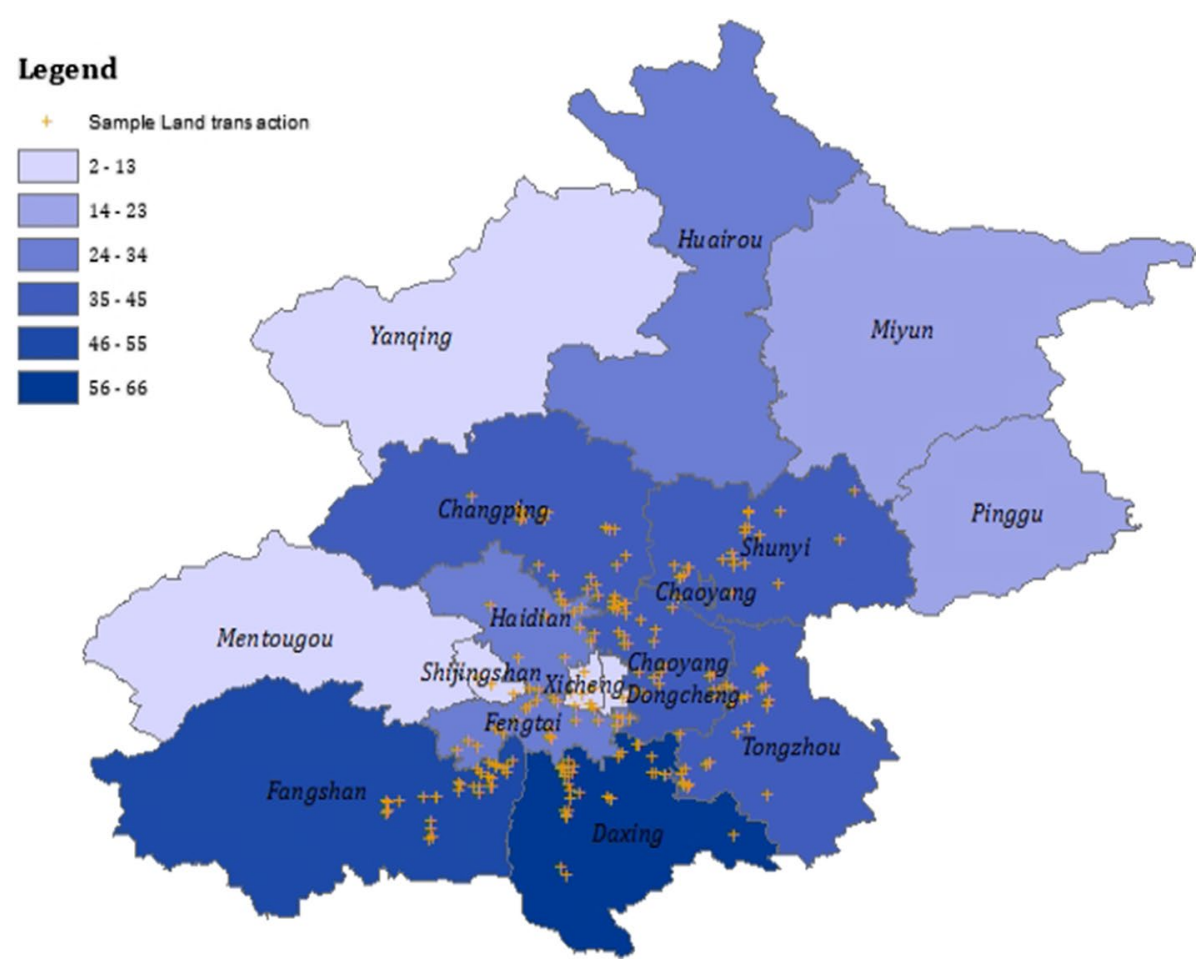

Fig. 3 Land Transaction in Municipal Districts. Sources Land transaction records are from Beijing Municipal Commission for City Planning and Land Resources Management (http://ghgtw.beijing.gov.cn)

The first part of the dataset is the land transaction data from Beijing Municipal Commission for City Planning and Land Resources Management (http://ghgtw.beijing.gov.cn). We collect records of 432 land lot transactions between 2003 and 2010. The information includes location, land area, construction area, floor area, land use type, benchmark price, transaction date, transaction price and the name of the real estate developer. We then match the land transaction data with monthly new home transaction records in Beijing from the Hang Lung Center for Real Estate of Tsinghua University. The matching gives 4899 home transaction records for 198 residential property development projects after dropping observations with missing values and incorrect records. ${ }^{7}$ Given the time lags from land transaction to property sales, the matched sales records are in the time range of 2006-2014. For each land lot, we calculate the distance to the city center, the nearest underground station, the nearest park, the nearest hospital and the nearest primary school with the location information. We also obtain real estate developers' ownership structure and listing status information from https://www.qichacha.com.

The sample size is not large comparing with most empirical works because of the nature of the research question. However, the dataset has ideal representativeness. It covers 11

\footnotetext{
7 More specifically, we exclude records that have missing values and outliers (land prices or house prices three standard deviations away from the average price in the same development projects). We also exclude errorneous records that have house sales date earlier than land leasing dates.
} 
Table 1 Summary statistics of key variables

\begin{tabular}{|c|c|c|c|c|c|}
\hline Variable name & Definitions & Mean & SD & Min & $\operatorname{Max}$ \\
\hline \multicolumn{6}{|c|}{ Land characteristics } \\
\hline DIST_CCT & Distance to city centre $(\mathrm{km})$ & 21.77 & 10.12 & 1.37 & 54.85 \\
\hline DIST_UGS & Distance to nearest underground station $(\mathrm{km})$ & 2.91 & 3.42 & 0.09 & 20.01 \\
\hline DIST_EPS & Distance to nearest elementary primary school (km) & 12.61 & 8.71 & 0.34 & 42.88 \\
\hline DIST_HSP & Distance to nearest hospital $(\mathrm{km})$ & 12.59 & 8.25 & 0.12 & 37.90 \\
\hline$D I S T \_P A R$ & Distance to nearest park (km) & 8.11 & 6.67 & 0.21 & 37.05 \\
\hline LANDAREA & Land area $\left(1000 \mathrm{~m}^{2}\right)$ & 90.44 & 79.28 & 1.72 & 638.00 \\
\hline FLOORAREA & Floor area $\left(1000 \mathrm{~m}^{2}\right)$ & 170.59 & 127.86 & 3.60 & 701.62 \\
\hline PUBLIC & Commercial use included & 0.34 & 0.48 & 0 & 1 \\
\hline COMMERCIAL & Public use included & 0.25 & 0.44 & 0 & 1 \\
\hline LPRICE & Land price (1000 yuan $\left./ \mathrm{m}^{2}\right)$ & 5.62 & 4.34 & 0.35 & 28.56 \\
\hline \multicolumn{6}{|c|}{ Project characteristics } \\
\hline$D E C O$ & Average decoration cost (yuan $\left./ \mathrm{m}^{2}\right)$ & 858.41 & $1,991.51$ & 0 & 13,500 \\
\hline FAR & Floor area ratio & 2.09 & 0.79 & 0.49 & 6.34 \\
\hline FEE & Property management fee (yuan $\left./ \mathrm{m}^{2}\right)$ & 3.18 & 1.86 & 0.00 & 17.60 \\
\hline SIZE & Average unit size $\left(\mathrm{m}^{2}\right)$ & 121.76 & 52.22 & 55.84 & 393.00 \\
\hline HPRICE & House price $\left(1000\right.$ yuan $\left./ \mathrm{m}^{2}\right)$ & 19.72 & 10.88 & 3.20 & 69.97 \\
\hline \multicolumn{6}{|c|}{ Developer characteristics } \\
\hline LISTED & Listed & 0.48 & 0.50 & 1 & 0 \\
\hline$P E$ & Private enterprise (All PEs in joint purchase) & 0.44 & 0.50 & 1 & 0 \\
\hline JOINT & Jointly purchased by more than one developer & 0.19 & 0.40 & 1 & 0 \\
\hline
\end{tabular}

out of 16 administrative districts in Beijing. ${ }^{8}$ Figure 3 demonstrates the distribution of the observations amongst administrative districts. ${ }^{9}$ The total number of land transactions recorded in each district between 2003 and 2010 is represented by different shades of blue, with dark colors representing high transactions. The four districts in the city core, i.e. Xicheng District, Dongcheng District, Xuanwu District and Chongwen District, have the smallest land transaction volume during the sampling period. Land transactions-as a proportion of the total land sales in the whole city-range between $0.01 \%$ (Dongcheng District) and $1.5 \%$ (Xuanwu District) in these districts. This result is because the majority of the land in the city core has already been fully developed or occupied with cultural heritages that are not allowed for redevelopment. Land transactions increase as the distance from the city center lengthens, such as in Daxing District (16.8\%) and Fangshan (15.3\%). We then overlay our sample points on the map with yellow crosses. The distribution of our sample points not only covers the most active parts of the land markets in Beijing but also resembles the geographical patterns of the population distribution closely.

Table 1 exhibits the descriptive statistics of variables that measure the characteristics of land, project and real estate developers. The average land price is $5617 \mathrm{RMB} / \mathrm{m} 2$ which is

\footnotetext{
${ }^{8}$ Five districts, i.e. Mentougou, Yanqing, Huairou, Miyun, and Pinggu, are omitted due to data availability.

9 Chongwen and Xuanwu were independent administrative districts before 2010, and they were merged into Dongcheng and Xicheng, respectively in 2010. In Fig. 3, we still treat them as independent districts because our sample period is mostly before 2010. Thus, samples distribute amongst 13 districts in Fig. 3.
} 
about one-third of the average house prices $(19,721 \mathrm{RMB} / \mathrm{m} 2)$. The standard deviations are high for most of the variables and in some cases even higher than the mean, thereby indicating the high heterogeneity amongst the development projects and developers.

\subsection{Models}

Following the theoretical framework, we describe the natural logarithm of developers' asking price for residential real estate development project $i\left(P_{i}\right)$ as a linear function of an indicator of loss $\left(\operatorname{LOSS}_{i}\right)$, the observable attributes $\left(\boldsymbol{X}_{i}\right)$, the indicator of the year when house sales take place $\left(\right.$ Year $\left._{i}\right)$, a constant $\left(\alpha_{0}\right)$ and the error term $\left(\varepsilon_{i t}\right)$. This specification is given in Eq. (4). The definition of $\left(\operatorname{LOSS}_{i}\right)$ can be found in Eq. (5), where $L_{i}$ is the actual land price; $r e f_{i}$ is the reference land price.

$\boldsymbol{X}_{i}$ is a vector of hedonic attributes of house prices. It includes physical characteristics such as decoration level when sold $(D E C O)$, floor to area ratio $(F A R)$, property management fee $(F E E)^{10}$, and average size of properties (SIZE), as well as locational characteristics such as distance to city center (DIST_CCT) and distance to subway station (DIST_SUB). According to the literature (Follain and Jimenez 1985; Sirmans et al. 2005), DECO and $F E E$ are expected to have a positive relationship with house prices; DIST_CCT and DIST $S U B$ usually have a negative relationship with house prices; signs for $F A R$ and $S I Z E^{11}$ are an empirical issue and differ in market settings. Some studies suggest that the shape and the frontage of land affect land prices (see, for example, Gao and Asami 2007). However, these factors are often omitted from hedonic price models when estimating land prices in high-density urban areas in China, where parcel shape and frontage are fairly uniform and regular. For example, in studies of land prices in Beijing (Ding and Zhao 2014; Yang et al. 2015), Wuhan (Qu et al. 2020), and Hangzhou (Wen et al. 2018), neither the shape nor the frontage of land is considered in the hedonic price models. Following the practice in the literature, we do not include lot shape and frontage in our hedonic price models.

Year $_{i, t}$ equals one in the year of sales in project $i$, and zero otherwise. Note that all sales in our database occurred between 2006 and 2014, and Year $_{2006}$ is dropped as the base category. Although the 2007/08 financial crisis brought the house price growth rate in China down to a record low in 2008, the negative effect is short-lived. Chinese government responded swiftly to the crisis by introducing a stimulus package of 4 trillion yuan (approx. $\$ 586$ billion) in September 2008. China's economy growth rate was boosted by 5-7\% in 2009 and the following years (Diao et al. 2012). A substantial amount of this stimulus package went into the real estate sector directly and indirectly (see Table 1 in McKissack and $\mathrm{Xu}$ 2011, page 48). The Chinese government also introduced a series of plans to stabilise house prices, such as lowering the one-year benchmark lending rate and deposit rate of financial institutions, reducing the minimum down payment ratio to $20 \%$, and waiving property transfer taxes. As a result, housing prices rocketed by $9.5 \%$ in 2009 , with growth rates as high as $70 \%$ year-on-year in some metropolitan areas (see the discussion in Dai et al. 2020, page 563). As a result, we do not consider the effect of the financial crisis in this study.

\footnotetext{
10 Property management fee is included because all properties in our sample are leasehold apartment units. It is an important determinant of house prices in China

11 Note that we use the house price per square meter as the dependent variable. If the total house price is used, the sign for SIZE coefficient is usually positive.
} 
We take all measurements at the project level. For instance, $P_{i}$ is the average asking price of all saleable housing units in project $i$ in the year of investigation.

$$
\begin{gathered}
P_{i}=\alpha_{0}+\alpha_{1} \text { LOSS }_{i}+\boldsymbol{X}_{i} \boldsymbol{\beta}+\sum_{t=2007}^{2014} \delta_{t} \text { Year }_{i, t}+\varepsilon_{i t} \\
\text { LOSS }_{i}=\left\{\begin{array}{l}
1, r e f_{i}-L_{i}<0 \\
0, r e f_{i}-L_{i} \geq 0
\end{array}\right.
\end{gathered}
$$

In this specification, if $\alpha_{1}$ is substantially greater than zero, then prior losses are associated with high asking prices that developers set in the later stage of home sales.

Real estate development is a long and complex process, during which developers generally make constant adjustments to their strategies. This condition is particularly true during the sales stage of this process. Developers commonly sell housing units within the same project in phases, even if all units have already been completed. This approach allows developers to adjust listed prices such that any mispricing in previous sales could be corrected. Investigating if developers can overcome loss aversion as additional market information comes in (i.e. as sales progresses through multiple phases) is important. Therefore, we adopt two variations of Eq. (4) to investigate the initial effect of loss aversion and the overall effect of loss aversion throughout the sales period.

To investigate the initial effect of loss aversion, we consider sales in the first year of the sales period only. For project $i$, let $t_{1}$ be the first year of the sales period. Section 6 describes the model specification. $P_{i, 1}$ is the natural logarithm of the average asking price of all saleable housing units in project $i$ in the first year of the sales period ${ }^{12}$. Coefficient $\alpha_{1}$ captures the isolated, net effects of loss aversion. $\delta_{t 1}$ is the year fixed effects that captures the influences from any other factors that are not included in $\boldsymbol{X}_{i}$.

$$
P_{i, 1}=\alpha_{0}+\alpha_{1} \operatorname{LOSS}_{i}+\boldsymbol{X}_{i} \boldsymbol{\beta}+\sum_{t 1=2007}^{2014} \delta_{t 1} \text { Year }_{i, t 1}+\varepsilon_{i, 1}
$$

To investigate the overall effect of loss aversion, we augment Eq. (4) to include sales in the whole project sales period, as shown in Eq. (7). In our sample, the maximum length of sales period is eight years (i.e. developers spent up to eight years to sell all units in their projects). We create eight dummy variables (i.e. $T_{j}$, where $j=1,2,3, \ldots 8$ ) to indicate the different years when sales occurred during the sales period. Note that the dummy variable for the first year of sales period is omitted from Eq. (7) because the effect has already been captured by $\delta_{t 1}$. We then create interaction terms between $L O S S_{i}$ and $T_{j}$ to capture the effect of loss aversion, if any, in each year of the sales period. $T_{j}$ is also included in Eq. (7) to control for any other project-year specific effects other than loss aversion. $P_{i, n}$ is the average asking price of all saleable housing units in project $i$ in the $n$th year of investigation. If a project took $N$ years to sell out all of its units, then a total of $N$ observations will be created for this project, one for each of the year within the sales period.

\footnotetext{
12 It is a common practice to use natural logarithm in empirical housing studies because house prices are usually right-skewed (see, for example, the discussion in Qu et al. 2020, page 3). We adopted this approach for the same reason
} 


$$
P_{i, n}=\alpha_{0}+\alpha_{1} \operatorname{LOSS}_{i}+\boldsymbol{X}_{i} \boldsymbol{\beta}+\sum_{t 1=2007}^{2014} \delta_{t 1} \text { Year }_{i, t 1}+\sum_{j=2}^{8} \delta_{j} T_{j}+\sum_{j=2}^{8} \alpha_{j} L_{O S S_{i}} \times T_{j}+\varepsilon_{i, n}
$$

The overall or accumulative effect of loss aversion for the whole sales period can be constructed with the coefficient estimates of $\operatorname{LOSS}_{i}$ and its interaction terms in Eq. (7). If it took three years for a project to sell all the completed units, then the accumulative loss aversion effect in year one, two, and three can be calculated as $\hat{\alpha}_{1}, \hat{\alpha}_{1}+\hat{\alpha}_{2}$, and $\hat{\alpha}_{1}+\hat{\alpha}_{2}+\hat{\alpha}_{3}$ respectively.

\subsection{Reference point determination}

Identifying reference point is crucial for the estimation of Eqs. (6) and (7). If the reference point is defined incorrectly, the developers might be placed in the wrong domain, and subsequently the measurement of losses could be wrong. This condition would render the whole analysis invalid. Unfortunately, prospect theory offers no clear guidance regarding the identification of reference points. In real estate loss aversion literature, the most commonly used reference point is previous purchase (Anenberg 2011; Bokhari and Geltner 2011; Genesove and Mayer 2001; Leung and Tsang 2013). The advantage of such an approach is that previous purchase prices are observable and salient. However, this solution is not feasible for our analysis due to the very nature of land transaction and the land market in China because all of the land auctions in the country are the very first sales. No previous transaction information is available. To circumvent this data availability issue, we estimate the reference point by calculating the inverse distance weighted average price of comparable land transactions in the neighbourhood. The estimation steps are as follows.

For each land lot $i$, we firstly implement a radius search to identify comparable land sales. The choice of radius is important. A smaller radius gives closer and thus more comparable land parcels to land lot $i$. Nevertheless, a smaller search radius also can result in an insufficient number of parcels. Unfortunately, theories do not provide guidance on the exact specification of search radiuses. The choice of the cut-off distance is an empirical issue and can even vary among studies using data from the same geographic area. For example, both a $3 \mathrm{~km}$ and an $1 \mathrm{~km}$ radius are used in spatial analysis of house prices in Seoul, South Korea (Hyun and Milcheva 2018, 2019). We follow the practice in the literature by determining the search radius empirically. We explored various radiuses and found that the 5 miles radius is the smallest one that gives sufficient sample size for our estimation. It provides a good balance between precision and robustness. We then identify a total of $Q_{i}$ comparable land transactions for land lot $i$ within the 5 miles radius. Given that not all comparable land sales occurred in the same year, we discount the prices to year 2003. The discount rate, denoted as $r_{\text {year }}$, is the cumulative land price growth rate between the year of land transaction (year) and 2003. For instance, for a comparable land lot $j$ in 2007, if the transaction price is $p_{j}$, the 2003 price is $p_{j}^{*}=\frac{p_{j}}{1+r_{2007}}$.

We also use an inverse distance weighting method to aggregate the prices of the $Q_{i}$ comparable land transactions. The inverse distance weighting method ensures that closer transactions have high weights, whereas transactions further away have their contributions diminishing with distances. Let $k_{i j}=\frac{1}{\text { distance }_{i j}}$, where distance $e_{i j}$ is the distance between land lot $i$ and a comparable land lot $j$. Accordingly, the 2003 price $p_{j}^{*}$ has a weight of 
Table 2 Land and house prices in the gain and loss domains

\begin{tabular}{lcrrrr}
\hline & Obs & \multicolumn{1}{l}{ Mean } & \multicolumn{1}{l}{$S D$} & Min & Max \\
\hline Panel A. Loss domain & & & & & \\
$\quad$ \# Comparable land lots & 82 & 11.35 & 5.61 & 1 & 23 \\
Reference price & 82 & 5412.66 & 2653.26 & 1210.38 & $12,574.76$ \\
Land price & 82 & 7457.50 & 3704.49 & 1498.00 & $18,014.00$ \\
House price & 82 & $22,920.57$ & $12,379.52$ & 3217.41 & $69,970.85$ \\
Panel B. Gain domain & & & & & \\
\# Comparable land lots & 110 & 12.25 & 5.19 & 1 & 25 \\
Reference price & 110 & 5241.36 & 2650.09 & 1268.61 & $14,619.67$ \\
Land price & 110 & 3745.19 & 2240.85 & 347.00 & $12,523.00$ \\
House price & 110 & $16,906.57$ & 7457.71 & 3688.53 & $43,420.94$ \\
\hline
\end{tabular}

The unit for prices is 1000 yuan $/ \mathrm{m}^{2}$

$w_{i j}=\frac{k_{i j}}{k_{i 1}+k_{i 2}+\ldots+k_{i Q_{i}}}$. The estimated comparable land price as of year 2003 is the weighted average of discounted land prices of all $Q_{i}$ comparable land transactions, or $\sum_{j=1}^{Q_{i}} w_{i j} \times \frac{p_{i j}}{1+r_{\text {year }}}$.

Lastly, we convert the 2003 weighted average price to the year when land lot $i$ was purchased, with $r_{\text {year }}$. In sum, the formula to calculate the reference point is as Eq. (8).

$$
r e f_{i}=\left(1+r_{\text {year }}\right) \times \sum_{j=1}^{Q_{i}} w_{i j} \times \frac{p_{i j}}{1+r_{\text {year }_{j}}}
$$

\section{Results and discussions}

With the approach described in Sect. 4, we match each land transaction with transactions within a 5-miles radius and drop six land lots that have no comparable transactions. For the remaining 192 land lots, 12 comparable transactions emerge for each lot on average. We identify 82 land transactions in the loss domain and 110 in the gain domain. Table 2 contrasts land prices and house prices in the two domains. Whilst reference land prices are only slightly greater in the gain domain than in the loss domain, i.e. $5413 \mathrm{yuan} / \mathrm{m}^{2}$ and $5241 \mathrm{yuan} / \mathrm{m}^{2}$, land transaction price differences are much larger, i.e. $7458 \mathrm{yuan} / \mathrm{m}^{2}$ and $3745 \mathrm{yuan} / \mathrm{m}^{2}$. Thus, real estate developers in the loss domain purchase land lots of similar value at higher prices. The difference is great in the average house prices, i.e. 22,920 yuan $/ \mathrm{m}^{2}$ and $16,907 \mathrm{yuan} / \mathrm{m}^{2}$, which is consistent with our hypothesis that developers in the loss domain set high house prices to pursue breakeven.

Table 3 presents the Ordinary Least Squares (OLS) estimates of Eq. (6). The coefficient estimates of control variables and year fixed effects are significant with expected signs. For simplicity, we present coefficient estimates of key variables only in Table 3. In column (1), we present results by using all sample points. LOSS has a positive coefficient that is significant at the $1 \%$ level. The coefficient confirms that developers compare land transaction with the reference price, and previous losses from land purchases affect their pricing decisions for houses that are completed later on these land lots. Specifically, developers in the loss domain 
Table 3 Coefficient estimates of Eq. (6)

\begin{tabular}{llllll}
\hline Reference point & \multicolumn{4}{l}{ Within 5 miles (inverse distance weighted average) } \\
\cline { 2 - 6 } Sample & $(1)$ All & $(2)$ SOE & $(3)$ PE & (4) Listed & (5) Unlisted \\
\hline LOSS & $0.10^{* * *}$ & 0.04 & $0.12^{* * *}$ & 0.06 & $0.16^{* * *}$ \\
& $(0.03)$ & $(0.05)$ & $(0.05)$ & $(0.04)$ & $(0.05)$ \\
DECO & $3.97^{* * *}$ & $3.04^{*}$ & $4.31^{* * *}$ & $3.34^{* *}$ & $4.24^{* * *}$ \\
& $(0.98)$ & $(1.58)$ & $(1.33)$ & $(1.35)$ & $(1.18)$ \\
FAR & 0.03 & $0.13^{* * *}$ & 0.01 & 0.05 & 0.02 \\
& $(0.03)$ & $(0.03)$ & $(0.03)$ & $(0.05)$ & $(0.03)$ \\
FEE & $0.06^{* * *}$ & $0.08^{* * *}$ & $0.06^{* * *}$ & $0.08^{* * * *}$ & $0.05^{* * *}$ \\
& $(0.01)$ & $(0.02)$ & $(0.01)$ & $(0.02)$ & $(0.02)$ \\
SIZE & $1.03^{* *}$ & 0.63 & $1.01^{*}$ & 0.95 & $1.11^{* *}$ \\
& $(0.40)$ & $(0.68)$ & $(0.52)$ & $(0.58)$ & $(0.47)$ \\
DIST_CCT & $-2.33^{* * *}$ & $-2.43^{* * *}$ & $-2.17^{* * *}$ & $-1.81^{* * *}$ & $-2.83^{* * *}$ \\
& $(0.28)$ & $(0.41)$ & $(0.37)$ & $(0.40)$ & $(0.35)$ \\
DIST_SUB & -0.44 & -0.47 & -0.07 & $-1.66^{*}$ & 0.47 \\
& $(0.71)$ & $(1.12)$ & $(0.96)$ & $(0.99)$ & $(0.87)$ \\
Constant & $8.89^{* * *}$ & $8.69^{* * *}$ & $8.96^{* * *}$ & $8.91^{* * *}$ & $8.94^{* * *}$ \\
& $(0.13)$ & $(0.20)$ & $(0.16)$ & $(0.18)$ & $(0.15)$ \\
R-squared & 0.86 & 0.91 & 0.85 & 0.85 & 0.89 \\
Adj. R-squared & 0.85 & 0.89 & 0.82 & 0.82 & 0.87 \\
Number of obs & 191 & 86 & 105 & 99 & 92 \\
\hline
\end{tabular}

Standard errors in parentheses. Apart from the variables listed in the table, all regressions also include dummy variables for the transaction year. Their coefficients are significant and omitted from the table for simplicity

$* * * p<0.01 ; * * p<0.05 ; * p<0.1$

set asking prices for newly completed houses $10 \%$ higher than their counterparts in the gain domain.

\subsection{Ownership}

Existing evidence infers that state-owned enterprises (SOEs) and privately owned enterprises (PEs) behave differently, especially in their decisions directly associated with economic profits. Under state controls, SOEs sometimes forgo maximum economic profit in the pursuit of social and political benefits. For instance, SOEs usually have excessive labour inputs (Boycko et al. 1996), and they are pressured to hire politically connected people, rather than those best qualified (Krueger 1990). Thus, SOEs are less efficient and profit driven than PEs. SOEs typically have soft budget constraints and consequently less pressure from losing money (Kornai et al. 2003). Even in financial distress, they can always rely on the state to bail them out. Thus, they are not sensitive to financial losses. However, PEs do not have the backing from the state, and have to take responsibility for the bad decisions they made and the resultant losses. They should be responsive to prior losses. SOEs also have better access to external financing and lower cost of credit than PEs. They enjoy direct budgetary support from the government and preferential treatment by governmentowned financial institutions (Beck et al. 2006). Given the low cost of credit, a painful loss 
to PEs may not be as painful to SOEs. Moreover, SOEs may have limited freedom to adjust property price than private firms, because SOEs are controlled mainly by the government, who are less likely to cause price inflation in local property markets. On this note, the loss aversion behavior of SOEs is somewhat controlled by the government while PEs are not. Consequently, state-owned developers may be less motivated to set high house prices and pursue breakeven. The manner in which firm ownership structure moderates loss aversion effect must be tested.

A Chow Structural Break test on Eq. (6) confirms that the coefficient estimates for SOEs and PEs are not identical. Consequently, we estimate Eq. (6) using SOEs and PEs subsamples separately. The results are given in columns (2) and (3) in Table 3. We find that PEs are sensitive to losses. They set $12 \%$ higher asking prices when in the loss domain. However, no evidence of SOEs responds to land transaction losses. The results are in line with the existing literature as discussed previously. We conclude that the loss aversion premium estimated in the previous step, i.e. the $10 \%$ price increase estimated by using the full sample, is largely driven by the private sector.

\subsection{Listing status}

Development decisions are affected by developer's financial conditions (Stein 1995). The land acquisition fee to developers is similar as the down payment to home buyers in that a considerable amount of fund is required at the early stage of investment. In order to afford their next land acquisition deals, financially constrained developers are likely to have rigid reservation prices and more averse to losses in the development project he is currently working on. Non-financially constrained developers, however, are not influenced in the same fashion. Instead, they prioritise completing current development project and selling houses promptly so that they can move on to the next investment opportunities. In this sense, they optimise profits on a project level but rather on a firm level. Hence, loss aversion for non-constrained developers is small. To conclude, loss aversion level should be negatively related to developers' financial condition. Given that developer's financial data are not publicly available, we use their listing status to proxy their financial capability.

The extensive literature on initial public offering documents the relationship between stock listing and firm financial capability. These studies indicate that listed firms enjoy better access to financial resources (Pagano et al. 1998), lower cost of credit (Pagano et al. 1998) and enhanced financial flexibility (Beck et al. 2006; Schoubben and Van Hulle 2011) than unlisted firms. Therefore, we expect that firms that are listed on a stock exchange are less sensitive to losses than unlisted firms. Using the same strategy as outlined in Sect. 5.1, we test if listed and unlisted firms have different responses to prior losses. Again, a Chow Structural Break test confirms that the two types of firms behaved differently. We subsequently estimate Eq. (6) for listed firms and unlisted firms respectively. The results are given in columns (4) and (5) in Table 3. Unlisted developers are more sensitive to losses than unlisted developers. They set asking 16\% higher prices when they are in the loss domain. Listed developers, however, do not exhibit substantial loss aversion behaviour. Thus, the financial advantages provide listed companies with improved financial flexibility, and consequently cushions from temporary losses. The correlation between listed status and ownership structure in our sample is not high. For example, the correlation coefficient between the two variables is 0.4452 ; the proportion of listed companies is $77 \%, 33 \%$, and $52 \%$ for SOEs, PEs, and all companies combined, respectively. Therefore, the identified listing status effect is a separated issue from the ownership structure effect. 
Table 4 Coefficient estimates of Eq. (7)

\begin{tabular}{|c|c|c|c|c|c|}
\hline \multirow{2}{*}{$\begin{array}{l}\text { Reference point } \\
\text { Sample }\end{array}$} & \multicolumn{5}{|c|}{ Within 5 miles (inverse distance weighted average) } \\
\hline & (1) All & (2) $\mathrm{SOE}$ & (3) PE & (4) Listed & (5) Unlisted \\
\hline \multirow[t]{2}{*}{ LOSS } & $0.14 * * *$ & 0.09 & $0.16^{* *}$ & $0.11 * *$ & $0.15^{*}$ \\
\hline & $(0.05)$ & $(0.07)$ & $(0.07)$ & $(0.05)$ & $(0.09)$ \\
\hline \multirow[t]{2}{*}{$L O S S \times T \_2$} & $-0.08 *$ & -0.04 & $-0.10^{*}$ & $-0.09 *$ & -0.04 \\
\hline & $(0.04)$ & $(0.07)$ & $(0.06)$ & $(0.05)$ & $(0.08)$ \\
\hline \multirow[t]{2}{*}{$L O S S \times T \_3$} & $-0.10^{*}$ & -0.10 & -0.09 & -0.05 & -0.11 \\
\hline & $(0.06)$ & $(0.10)$ & $(0.08)$ & $(0.06)$ & $(0.11)$ \\
\hline \multirow[t]{2}{*}{$L O S S \times T \_4$} & 0.11 & -0.02 & $0.20 * *$ & 0.08 & 0.11 \\
\hline & $(0.07)$ & $(0.10)$ & $(0.10)$ & $(0.07)$ & $(0.13)$ \\
\hline \multirow[t]{2}{*}{$L O S S \times T \_5$} & 0.06 & 0.19 & 0.01 & -0.02 & 0.11 \\
\hline & $(0.13)$ & $(0.15)$ & $(0.18)$ & $(0.12)$ & $(0.19)$ \\
\hline \multirow[t]{2}{*}{$L O S S \times T \_6$} & 0.22 & 0.24 & 0.19 & 0.06 & $0.36^{* *}$ \\
\hline & $(0.15)$ & $(0.18)$ & $(0.21)$ & $(0.27)$ & $(0.16)$ \\
\hline \multirow[t]{2}{*}{$L O S S \times T \_7$} & 0.28 & 0.13 & $0.58 * *$ & 0.13 & $0.41 * *$ \\
\hline & $(0.22)$ & $(0.33)$ & $(0.24)$ & $(0.42)$ & $(0.19)$ \\
\hline \multirow[t]{2}{*}{$L O S S \times T \_8$} & $0.41 * *$ & $0.48^{*}$ & 0.22 & 0.25 & $0.50 * *$ \\
\hline & $(0.17)$ & $(0.26)$ & $(0.15)$ & $(0.21)$ & $(0.25)$ \\
\hline \multirow[t]{2}{*}{ Constant } & $9.90 * * *$ & $9.60 * * *$ & $9.91 * * *$ & $9.94 * * *$ & $9.82 * * *$ \\
\hline & $(0.15)$ & $(0.24)$ & $(0.21)$ & $(0.18)$ & $(0.22)$ \\
\hline Project fixed effect & YES & YES & YES & YES & YES \\
\hline Year fixed effect & YES & YES & YES & YES & YES \\
\hline Sales duration fixed effect & YES & YES & YES & YES & YES \\
\hline R-squared & 0.66 & 0.72 & 0.65 & 0.70 & 0.64 \\
\hline Adj. R-squared & 0.65 & 0.69 & 0.62 & 0.68 & 0.61 \\
\hline Number of Obs & 742 & 328 & 414 & 365 & 377 \\
\hline
\end{tabular}

Standard errors in parentheses. Apart from the variables listed in the table, all regressions also include control variables for property attributes, transaction years and sales duration. Their coefficients are significant and omitted from the table for simplicity

$* * * p<0.01 ; * * p<0.05 ; * p<0.1$

Fig. 4 Overall effect of loss aversion

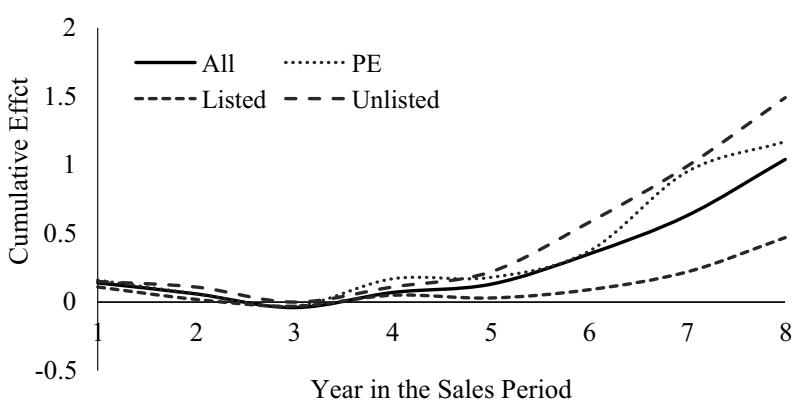




\subsection{Overall effect of loss aversion}

In the previous section, we document that prior losses affect developer's pricing strategy when the property enters the market. In this section, we further probe if this effect persists throughout the whole selling period with model specified in Eq. (7). We create one observation for each year of the project period, instead of only one observation in the first year of the project period in Eq. (6). The total number of observations in this step tripled from 191 to 742 because the average sales period is 2.89 years. Given that observations from the same project are related, we use clustered standard errors to correct any potential biases in the estimation. Similar to the estimation of Eq. (6), we have controlled for project, year and sales period duration fixed effects.

Table 4 shows the coefficient estimates of Eq. (7). We construct the accumulative effect of loss aversion over the entire project period based on Table 4, and plot the results in Fig. 4. SOEs are not included in Fig. 4 because the coefficient estimates of $L^{O S S}$ are insignificant across the board. The figure reveals a nonlinear relationship between the length of sales period and the effect of loss aversion on asking prices of newly completed apartments. If a project can sell out of its inventory within the first year, then the effect of loss aversion is estimated to be $14 \%$ of overpricing. Hence, developers' asking price is $14 \%$ higher than the fair market price. If it takes more than one year to clear the housing unit inventory, developers become rational in pricing the apartments in later stages of the sales. This change is evident from the downward slope of all curves from Year 1 to Year 3 in Fig. 4. However, if it takes more than three years to sell out the units, developers will become loss averse over the time. This result is not surprising given the average length of sales period in our sample is 2.89 years. When a project takes longer than usual (i.e. 2.89 years or 3 years) to sell out, developers become anxious about recovering land transaction loss. This result is also consistent with the findings in the studies of disposition effect, which is caused by loss aversion. Hence, the ones who are most prone to loss aversion effect are the least likely to sell at a loss, and thus likely to have the longest sales period. Therefore, loss aversion effect is the largest for projects with the longest sales period (i.e. 8 years in our sample).

\section{Robustness checks}

\subsection{Alternative reference point determinations}

In their influential paper, Kahneman and Tversky (1979) provided a few candidates for reference point, such as the status quo, the expectations of decision makers and the formulation of offered prospects. However, empirical difficulties arise when applying their theory. Specifically, reference points are often formed under the influence of heuristics and biases; they are unobservable, heterogeneous and possibly nonstationary (Allen et al. 2017). As such, the determination of reference points an empirical issue, and no hard and fast rule exists. On the one hand, this situation encourages and enables researchers to identify a wide range of reference points. On the other hand, it requires most behavioural studies to 
Table 5 Coefficient estimates of Eq. (7): alternative reference point

\begin{tabular}{|c|c|c|c|c|c|c|c|c|c|}
\hline \multirow{2}{*}{$\begin{array}{l}\text { Reference point } \\
\text { Sample }\end{array}$} & \multicolumn{5}{|c|}{$\begin{array}{l}\text { Within } 5 \text { miles (inverse distance weighted } \\
\text { average) }\end{array}$} & \multicolumn{4}{|c|}{ Hedonic valuation } \\
\hline & All & SOE & $\mathrm{PE}$ & Listed & Unlisted & SOE & PE & Listed & Unlisted \\
\hline LOSS & $\begin{array}{l}0.14 * * * \\
(0.05)\end{array}$ & $\begin{array}{l}0.09 \\
(0.07)\end{array}$ & $\begin{array}{l}0.16^{* *} \\
(0.07)\end{array}$ & $\begin{array}{l}0.11^{* *} \\
(0.05)\end{array}$ & $\begin{array}{l}0.15^{*} \\
(0.09)\end{array}$ & $\begin{array}{l}0.11^{*} \\
(0.06)\end{array}$ & $\begin{array}{l}0.13^{*} \\
(0.07)\end{array}$ & $\begin{array}{l}0.07 \\
(0.06)\end{array}$ & $\begin{array}{l}0.20^{* *} \\
(0.08)\end{array}$ \\
\hline$L O S S \times T \_2$ & $\begin{array}{l}-0.08^{*} \\
(0.04)\end{array}$ & $\begin{array}{l}-0.04 \\
(0.07)\end{array}$ & $\begin{array}{l}-0.10^{*} \\
(0.06)\end{array}$ & $\begin{array}{l}-0.09 * \\
(0.05)\end{array}$ & $\begin{array}{l}-0.04 \\
(0.08)\end{array}$ & $\begin{array}{l}-0.02 \\
(0.06)\end{array}$ & $\begin{array}{l}-0.04 \\
(0.06)\end{array}$ & $\begin{array}{l}-0.01 \\
(0.05)\end{array}$ & $\begin{array}{l}-0.04 \\
(0.08)\end{array}$ \\
\hline$L O S S \times T \_3$ & $\begin{array}{l}-0.10^{*} \\
(0.06)\end{array}$ & $\begin{array}{l}-0.10 \\
(0.10)\end{array}$ & $\begin{array}{l}-0.09 \\
(0.08)\end{array}$ & $\begin{array}{l}-0.05 \\
(0.06)\end{array}$ & $\begin{array}{l}-0.11 \\
(0.11)\end{array}$ & $\begin{array}{l}-0.02 \\
(0.09)\end{array}$ & $\begin{array}{l}-0.01 \\
(0.08)\end{array}$ & $\begin{array}{l}0.02 \\
(0.06)\end{array}$ & $\begin{array}{l}-0.07 \\
(0.10)\end{array}$ \\
\hline$L O S S \times T \_4$ & $\begin{array}{l}0.11 \\
(0.07)\end{array}$ & $\begin{array}{l}-0.02 \\
(0.10)\end{array}$ & $\begin{array}{l}0.20^{* *} \\
(0.10)\end{array}$ & $\begin{array}{l}0.08 \\
(0.07)\end{array}$ & $\begin{array}{l}0.11 \\
(0.13)\end{array}$ & $\begin{array}{l}0.00 \\
(0.08)\end{array}$ & $\begin{array}{l}0.13 \\
(0.10)\end{array}$ & $\begin{array}{l}0.08 \\
(0.07)\end{array}$ & $\begin{array}{l}0.04 \\
(0.11)\end{array}$ \\
\hline$L O S S \times T \_5$ & $\begin{array}{l}0.06 \\
(0.13)\end{array}$ & $\begin{array}{l}0.19 \\
(0.15)\end{array}$ & $\begin{array}{l}0.01 \\
(0.18)\end{array}$ & $\begin{array}{l}-0.02 \\
(0.12)\end{array}$ & $\begin{array}{l}0.11 \\
(0.19)\end{array}$ & $\begin{array}{l}0.07 \\
(0.13)\end{array}$ & $\begin{array}{l}0.07 \\
(0.13)\end{array}$ & $\begin{array}{l}-0.00 \\
(0.10)\end{array}$ & $\begin{array}{l}0.13 \\
(0.14)\end{array}$ \\
\hline Constant & $\begin{array}{l}0.14 * * * \\
(0.05)\end{array}$ & $\begin{array}{l}0.09 \\
(0.07)\end{array}$ & $\begin{array}{l}0.16^{* *} \\
(0.07)\end{array}$ & $\begin{array}{l}0.11 * * \\
(0.05)\end{array}$ & $\begin{array}{l}0.15^{*} \\
(0.09)\end{array}$ & $\begin{array}{l}9.65^{* * *} \\
(0.22)\end{array}$ & $\begin{array}{l}9.82 * * * \\
(0.21)\end{array}$ & $\begin{array}{l}9.93^{* * *} \\
(0.18)\end{array}$ & $\begin{array}{l}9.67 * * * \\
(0.22)\end{array}$ \\
\hline $\begin{array}{l}\text { Project fixed } \\
\text { effect }\end{array}$ & YES & YES & YES & YES & YES & YES & YES & YES & YES \\
\hline Year fixed effect & YES & YES & YES & YES & YES & YES & YES & YES & YES \\
\hline $\begin{array}{l}\text { Sales duration } \\
\text { fixed effect }\end{array}$ & YES & YES & YES & YES & YES & YES & YES & YES & YES \\
\hline R-squared & 0.66 & 0.72 & 0.65 & 0.70 & 0.64 & 0.75 & 0.68 & 0.75 & 0.67 \\
\hline Adj. R-squared & 0.65 & 0.69 & 0.62 & 0.68 & 0.61 & 0.73 & 0.67 & 0.74 & 0.65 \\
\hline Number of obs & 742 & 328 & 414 & 365 & 377 & 298 & 397 & 344 & 351 \\
\hline
\end{tabular}

Standard errors are enclosed in parentheses. Apart from the variables listed in the table, all regressions also include control variables for property attributes, transaction years and sales duration. Their coefficients are significant and excluded from the table for simplicity

$* * * p<0.01 ; * * p<0.05 ; * p<0.1$

establish the robustness of their findings to different choices of reference points. In this section, we present results using an alternative definition of reference point in the estimation of Eqs. (6) and (7) to verify the robustness of our findings.

We consider a rational version of reference point, i.e. land price valuation based on hedonic price modelling. Real estate developers are professionals who know their markets and products well. Their knowledge and experience will help them form the reference point based on their implicit estimation of the land prices, especially when land lots are in areas with less frequent transactions. We adopt hedonic pricing technique to capture this implicit valuation process based on land hedonic characteristics. This technique has been widely used in the studies of land prices ${ }^{13}$.

\footnotetext{
13 It was developed from theory of consumer behaviour, which suggests that commodities are valued for their individual utility-bearing attributes or characteristics (Rosen 1974). Various studies have explored this model in terms of attribute selection (Geoghegan et al. 1997; Tse 2002), functional form specification (Halvorsen and Pollakowski 1981) and possible biases involved in the valuation method (Dombrow et al. 1997). For recent applications, see for example, Polloni (2019) and Liang et al. (2020).
} 
The valuation-based reference point also attempts to mitigate the endogeneity problems in the comparable transactions method. The comparable transaction approach for reference determination bears the drawback that the difference between the reference transactions and the price of subject land transactions, i.e. the loss term, captures idiosyncratic characteristics that might affect both the land prices and property prices. When the land transaction price is lower than other transactions in the vicinity because the subject land parcels have some idiosyncratic characteristics, the perceived loss term is correlated with the property price. The problem is largely mitigated when those characteristics are accounted for in the land valuation procedure.

We develop the valuation-based reference point by adopting a semi-log model specification that is routinely used in the literature (Colwell and Munneke 1997). The model specification is shown in Eq. (9).

$$
L_{i}=\theta_{0}+\boldsymbol{Y}_{i} \boldsymbol{\theta}_{1}+\boldsymbol{T}_{i} \boldsymbol{\theta}_{2}+\varepsilon_{i,}
$$

where $L_{i}$ is the natural logarithm of land price per square meter for land parceli; $\boldsymbol{Y}_{i}$ is a $\mathrm{k} \times 1$ vector of explanatory variables including locational attributes, physical attributes, land use and developer characteristics; $\boldsymbol{T}_{i}$ is a set of binary dummy variables which equals 1 only in the year of land transaction; $\theta_{1}$ and $\theta_{2}$ are coefficients to be estimated; $\varepsilon_{i}$ is identically and independently distributed errors.

The choice of independent variables and the estimates of Eq. (9) can be found in Appendix. We then use the predicted land value as developer's reference point, i.e. $\hat{L}_{i}=r e f_{i}$ and calculate the indictor of losses in Eq. (3) accordingly. Table 5 presents the new OLS estimates. Loss coefficients have similar positive signs and are of similar magnitudes as in Sect. 5. Thus, the presence of loss aversion is confirmed. PEs and unlisted firms are still significantly loss averse, with coefficients of 0.13 and 0.20 , respectively. SOEs and listed firms are still less loss averse than their counterparts. Therefore, our conclusion still holds that PEs and unlisted firms are more sensitive to losses than SOEs and listed firms.

The overall effect of loss aversion also exhibits nonlinear relationship with the year in the sales period, as demonstrated in Fig. 5. We did not report the estimated overall loss aversion effects for years 6 to 8 because observation numbers are insufficient (i.e. less than 20 data points) to obtain reliable estimations. This condition is an inherent shortcoming for the hedonic price modelling approach, which is more data intensive than the weighted average comparable prices approach used in Sect. 5. Figure 5 suggests that the overall loss aversion effect decreases from year 1 to year 3, and gradually bounces up since the fourth year. The pattern is very similar to that in Fig. 4. Overall, our conclusions remain the same when the alternative definition of reference point is used.

Fig. 5 Overall effect of loss aversion (valuation-based reference point)

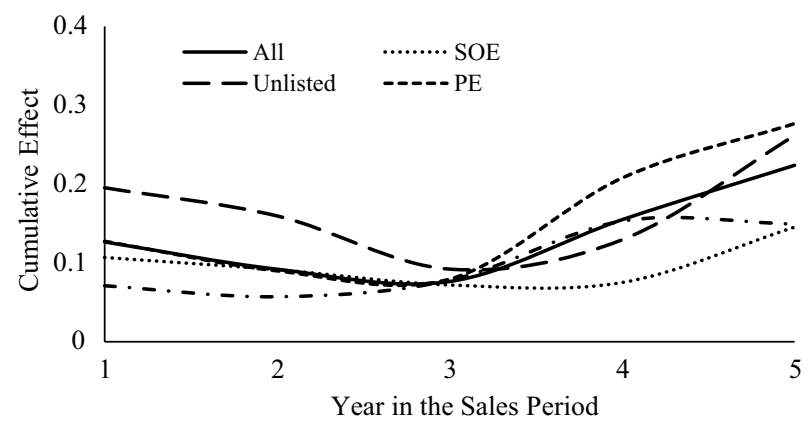




\subsection{Alternative measurements of loss}

In Sect. 4.2, we define LOSS as a dummy variable. This approach is adopted because the high multicollinearity between a continuous measurement of LOSS and its interaction terms with time dummy $T_{j}$ biases the estimation of Eq. (7). In this section, we re-estimate only Eq. (6) with the continuous measurement of LOSS (as defined in Eq. 3) to check the sensitivity of our findings to alternative definitions of LOSS. We firstly estimate the following equation.

$$
P_{i}=\alpha_{0}+\alpha_{1} D E V_{i}+\alpha_{2} D E V_{i}^{2}+\alpha_{3} D E V_{i} \times \operatorname{LOSS}_{i}+\alpha_{4} D E V_{i}^{2} \times L O S S_{i}+X_{i} \beta+\sum_{t 1=2007}^{2014} \delta_{t 1} \text { Year }_{i, t 1}+\varepsilon_{i}
$$

where $D E V_{i}$ is the deviation of the actual land price from the reference price, and $L O S S_{i}$ is as defined in Sect. 4.2. We include the squared term of $D E V_{i}$ to capture the nonlinear relationship between $D E V_{i}$ and $P_{i}$, if any. The results are given in Table 6 . We include a benchmark model 1 in Table 6 to facilitate comparisons. It does not contain the squared term of $D E V_{i}$ to account for the nonlinear relationship. Model 2 is corresponding to Eq. (10) above.

Although model 2 shows signs of improvement over model 1, the coefficient estimates of $D E V \times L O S S$ and $D E V^{2} \times L O S S$ are not significant. This may due to multicollinearity, as indicated by the very high variance inflation factors (VIFs hereafter) for $D E V \times L O S S$ and $D E V^{2} \times L O S S$. The model's specification may not be flexible enough to capture the nonlinear relationship between $D E V_{i}$ and $P_{i}$ either. Specifically, developers may mentally classify gains and losses into small, medium, or large ones, instead of treating them as continuous variables. Hence, we split losses and gains into small, medium and large by their magnitudes with the 25 th and 75 th percentiles and estimate the following specification.

$$
\begin{aligned}
& P_{i}=\alpha_{0}+\alpha_{1} D E V_{i} \times \operatorname{LOSS}_{\text {small } i}+\alpha_{2} D E V_{i} \times \operatorname{LOSS}_{\text {medium } i}+\alpha_{3} D E V_{i} \times \operatorname{LOSS}_{\text {larg } e}+\alpha_{4} D E V_{i} \times \\
& \operatorname{GAIN}_{\text {small i }}+\alpha_{5} D E V_{i} \times \operatorname{GAIN}_{\text {medium } i}+\alpha_{6} D E V_{i} \times \operatorname{GAIN}_{\text {arg } i}+X_{i} \beta+\sum_{t 1=2007}^{2014} \delta_{t 1} Y_{\text {Year }} r_{i, t 1}+\varepsilon_{i}
\end{aligned}
$$

where $\operatorname{LOSS}_{\text {small } i}=1$ if a developer's expected loss is below the 25th percentile, $\operatorname{LOSS}_{\text {medium } i}=1$ if a developer's expected loss is between the 25 th and the 75 th percentile, and $L O S S_{l \arg e i}=1$ if a developer's expected loss is above the 75th percentile. GAIN small , $G A I N_{\text {medium } i}$, and $G A I N_{\text {larg e } i}$ are defined in the same way in the gain domain. The flexible functional form in Eq. (11) can capture the effect of both loss aversion and diminishing marginal benefits. If the coefficient estimates of $\alpha_{1}, \alpha_{2}$, and $\alpha_{3}$ are negative and their absolute values are greater than those of $\alpha_{4}, \alpha_{5}$, and $\alpha_{6}$, we find evidence of loss aversion. If $\left|\alpha_{1}\right|>\left|\alpha_{2}\right|>\left|\alpha_{3}\right|$, or $\left|\alpha_{4}\right|>\left|\alpha_{5}\right|>\left|\alpha_{6}\right|$, there is diminishing marginal benefits in the loss or the gain domain.

The results are given in the Model 3 column in Table 6. First, the coefficient estimates suggest both loss aversion and diminishing marginal benefits. The coefficient estimates in the loss domain are $\hat{\alpha}_{1}=-2.58, \hat{\alpha}_{2}=-0.51$, and $\hat{\alpha}_{3}=-0.19$. This means that for each additional RMB of expected loss, developers will raise the selling price by $2.58,0.51$, or $0.19 \mathrm{RMB}$ when the size of the expected loss is in the small, medium, or large range. The absolute values of these coefficient estimates are larger than their counterparts in the gain domain, which are $\hat{\alpha}_{4}=1.77, \hat{\alpha}_{5}=-0.10$, and $\hat{\alpha}_{6}=-0.08$, respectively. We found clear evidence of loss aversion. 
Table 6 Coefficient estimates of Eq. (6) using alternative loss measurements

\begin{tabular}{|c|c|c|c|c|c|c|}
\hline & \multicolumn{2}{|l|}{ Model 1} & \multicolumn{2}{|l|}{ Model 2} & \multicolumn{2}{|l|}{ Model 3} \\
\hline & $\begin{array}{l}\text { Coef } \\
\text { (St. Err) }\end{array}$ & VIF & $\begin{array}{l}\text { Coef } \\
\text { (St. Err) }\end{array}$ & VIF & $\begin{array}{l}\text { Coef } \\
\text { (St. Err) }\end{array}$ & VIF \\
\hline$D E V$ & $\begin{array}{l}-0.18 * * \\
(0.07)\end{array}$ & 2.85 & $\begin{array}{l}-0.06 \\
(0.17)\end{array}$ & 18.57 & & \\
\hline$D E V^{2}$ & & & $\begin{array}{l}-0.10 \\
(0.15)\end{array}$ & 7.46 & & \\
\hline$D E V \times L O S S$ & $\begin{array}{l}0.10 \\
(0.12)\end{array}$ & 2.80 & $\begin{array}{l}-0.14 \\
(0.40)\end{array}$ & 23.77 & & \\
\hline$D E V^{2} \times L O S S$ & & & $\begin{array}{l}-0.03 \\
(0.34)\end{array}$ & 11.06 & & \\
\hline$D E V \times L O S S_{\text {small }}$ & & & & & $\begin{array}{l}-2.58 * * \\
(1.02)\end{array}$ & 1.54 \\
\hline$D E V \times L O S S_{\text {medium }}$ & & & & & $\begin{array}{l}-0.51^{* *} \\
(0.21)\end{array}$ & 2.30 \\
\hline$D E V \times L O S S_{\text {large }}$ & & & & & $\begin{array}{l}-0.19^{* *} \\
(0.09)\end{array}$ & 1.98 \\
\hline$D E V \times G A I N_{\text {small }}$ & & & & & $\begin{array}{l}1.77 * * * \\
(0.67)\end{array}$ & 1.60 \\
\hline$D E V \times G A I N_{\text {medium }}$ & & & & & $\begin{array}{l}-0.10 \\
(0.18)\end{array}$ & 2.19 \\
\hline$D E V \times G A I N_{\text {large }}$ & & & & & $\begin{array}{l}-0.08 \\
(0.09)\end{array}$ & 1.98 \\
\hline$D E C O$ & $\begin{array}{l}3.77 * * * \\
(1.07)\end{array}$ & 1.38 & $\begin{array}{l}3.68 * * * \\
(1.10)\end{array}$ & 1.41 & $\begin{array}{l}3.72 * * * \\
(1.08)\end{array}$ & 1.39 \\
\hline FAR & $\begin{array}{l}0.04 \\
(0.03)\end{array}$ & 1.47 & $\begin{array}{l}0.04 \\
(0.03)\end{array}$ & 1.48 & $\begin{array}{l}0.05 * \\
(0.03)\end{array}$ & 1.49 \\
\hline FEE & $\begin{array}{l}0.07 * * * \\
(0.01)\end{array}$ & 1.59 & $\begin{array}{l}0.07 * * * \\
(0.02)\end{array}$ & 1.61 & $\begin{array}{l}0.07 * * * \\
(0.01)\end{array}$ & 1.60 \\
\hline SIZE & $\begin{array}{l}1.32 * * * \\
(0.50)\end{array}$ & 1.69 & $\begin{array}{l}1.33 * * * \\
(0.51)\end{array}$ & 1.70 & $\begin{array}{l}1.31 * * * \\
(0.46)\end{array}$ & 1.70 \\
\hline DIST_CCT & $\begin{array}{l}-1.81^{* * *} \\
(0.30)\end{array}$ & 2.34 & $\begin{array}{l}-1.84 * * * \\
(0.30)\end{array}$ & 2.42 & $\begin{array}{l}-1.84 * * * \\
(0.29)\end{array}$ & 2.37 \\
\hline$D I S T \_S U B$ & $\begin{array}{l}-1.54^{*} \\
(0.88)\end{array}$ & 1.69 & $\begin{array}{l}-1.48 \\
(0.96)\end{array}$ & 1.75 & $\begin{array}{l}-1.73^{*} \\
(0.90)\end{array}$ & 1.72 \\
\hline Constant & $\begin{array}{l}10.02 * * * \\
(0.14)\end{array}$ & & $\begin{array}{l}10.01 * * * \\
(0.15)\end{array}$ & & $\begin{array}{l}9.94 * * * \\
(0.13)\end{array}$ & \\
\hline R-squared & 0.67 & & 0.67 & & 0.68 & \\
\hline Adj. R-squared & 0.65 & & 0.65 & & 0.67 & \\
\hline Number of obs & 742 & & 742 & & 742 & \\
\hline
\end{tabular}

Standard errors in parentheses. Apart from the variables listed in the table, all regressions also include dummy variables for the transaction year. Their coefficients are significant and omitted from the table for simplicity

$* * * p<0.01 ; * * p<0.05 ; * p<0.1$ 
Second, $\left|\hat{\alpha}_{1}\right|>\left|\hat{\alpha}_{2}\right|>\left|\hat{\alpha}_{3}\right|$ in the loss domain. This supports the notion of diminishing marginal benefits, or developers' response to loss changes decreases as the size of loss increases. In the gain domain, only the coefficient estimate in the small gain range is significant and positive. It indicates that when gains are small, developers are motivated to increase prices. A plausible reason for the result is developers' effort to secure a profitable position in a highly volatile market. Specifically, when expected gain is small the probability of falling into the loss domain when market prices fluctuate unexpectedly is not negligible. Therefore, developers in the small gain range will try to increase property prices to play it safe. This is not necessary when expected gains are in the medium or high range. Consequently, the coefficient estimates for $\alpha_{5}$ and $\alpha_{6}$ are not statistically significant (i.e., essentially zero). The overall pattern of these three coefficients still suggest the presence of diminishing marginal benefits, because the coefficient estimate in the small gain domain is the largest.

The findings are largely in line with results in Tables 4 and 5. Loss aversion is confirmed, and the effects of control variables are consistent across models. Our findings are not sensitive to alternative measurements of loss either. Although the model specification in Eq. (11) is more flexible than that in Eqs. (6) and (7), and it also can facilitate the analysis of relationships in the gain domain, we did not adopt this specification in Sect. 4. This is because the VIFs for some of the variables, such as $D E V_{i} \times G A I N_{\text {medium } i}$ and $D E V_{i} \times G A I N_{\text {large } i}$ are over 5 in Model 3 already. When time dummies $T_{j}$ are added to the model, multicollinearity becomes too serious to obtain reliable estimates.

\section{Conclusions}

Using land transaction and apartment sales data in Beijing, this paper shows that prior losses from land transactions affect developer's pricing decisions for new homes. The effects are also moderated by ownership structures and listing status of the developers. We find that SOEs or listed firms are not sensitive to prior losses in land transactions when pricing their newly completed apartments. The loss aversion effect is strong in the first year and towards the end of the sales period. Our findings add to the existing literature in the following ways.

Firstly, this paper contributes to the emerging behavioural research in the housing market, a promising area that will improve our knowledge on the micro-foundations of the market (Maclennan and O'Sullivan 2011). Whilst the presence of loss aversion in householdlevel decisions has been proven, behavioural studies on real estate developers' decisions are lacking. Developers play crucial roles in both the land and the housing markets. Cognitive bias in their behaviours, if any, will potentially affect both markets. In comparison with the general public, real estate developers are more experienced and knowledgeable of the market. They work in groups and make decisions with higher stakes. Consequently, they are less likely to be affected by behavioural or cognitive biases (Charness and Sutter 2012; Cooper and Kagel 2005). Nevertheless, we identify strong evidence of reference dependence and loss aversion amongst Chinese real estate developers. Thus, the persistence and robustness of reference dependence and loss aversion are confirmed as have been found in other studies (see, for example, Pope and Schweitzer 2011). We further contribute by identifying the time-varying feature of rationality, which is in line with the recent findings by (Glode et al. 2009) on mutual fund investors' behaviour. 
Secondly, our findings also shed lights on ways to mitigate or even eliminate loss aversion effects. As discussed previously, experience and high stakes cannot help real estate developers overcome loss aversion. Nevertheless, SOEs do not exhibit loss aversion effect at all, whilst listed firms are less affected than their unlisted counterparts. Thus an effective way for SOEs and listed firms to overcome loss aversion is to write off prior losses as sunk costs, partially or completely. Specifically, SOEs view losses from land transactions as sunk costs and write them off implicitly, knowing that the costs will be borne by the states. Therefore, their decisions about house prices are not affected by prior losses. Similarly, listed firms have better access to financing and are often of much larger scale than unlisted firms in China. They are more likely to recognise prior land transaction losses as sunk cost and behave more rationally in deciding the listing prices of new apartments. As such, the effect of loss aversion is overcome, albeit partially. This finding, once again, confirms the persistent nature of loss aversion. One cannot easily overcome loss aversion through practice or by using willpower. The most effective way is to write off the loss, or move the decision maker out of the loss domain.

Results also have implications for our understanding of the Chinese real estate markets. Whether high land prices are to blame for the overheating in housing market in China or not is a hot topic for debate (Glaeser et al. 2017; Wang et al. 2020; Wang and Zhang 2014). Although our paper does not answer this question directly, the findings deduce that land overpricing is likely to spillover to housing market. As developers are reluctant to write off losses from overbidding in land auctions, overpricing mistakes in land market will not be corrected in the pricing decisions in the housing market. This condition will push up the price in housing market accordingly. If the central government of China wants to cool down the housing market-which is one of the strategic priories in the recent five-years plan of the nation - then it should look upstream, i.e. the land market, to find an effective solution. Our findings present yet another evidence that the land and housing markets in China are closely intervened, and should not be studied or regulated in isolation (Bourassa et al. 2011; Kok et al. 2014).

"Chinese urbanisation and processes are so different from both western and other developing country experiences that it is difficult to subsume them." (Hamnett 2020, page 697). Therefore, it is necessary to test established behavioural theories in Chinese context. Findings from our study will be useful for policy makers and practitioners in other Chinese cities with similar market conditions. Meanwhile, a key finding in this paper is that government interventions in the form of supply restrictions will provide fertile ground for behavioural anomalies such as loss aversion. This is not a 'Chinese characteristic' anymore, because there are many regions and cities in other parts of the world, such as London, San Francisco and Hong Kong, where housing supply is significantly constrained by planning regulations and public housing policies. Our findings are relevant to the assessment of the behavioural aspects of urban planning and housing policies in those areas too.

\section{Appendix}

We follow the land valuation literature to select the independent variables in Eq. (9). The first group is the locational attributes, including the distance to the city centre, distance to the nearest amenities, i.e. underground station, primary school, park and hospital. They normally affect house prices negatively. The second group comprises two binary variables indicating land use restrictions, i.e. commercial use and public use. All land parcels in our 
Table 7 Land hedonic valuation estimates

\begin{tabular}{lll}
\hline Explanatory variable & Coef & Std. Err \\
\hline Distance to the city centre (m) & -1.151 & 1.179 \\
Distance to the nearest underground station $(\mathrm{m})$ & 2.398 & 1.325 \\
Distance to the nearest primary school (m) & -3.497 & 1.705 \\
Distance to the nearest park (m) & 2.089 & 1.035 \\
Distance to the nearest hospital (m) & -2.101 & 1.542 \\
Floor-area-ratio & 0.002 & 0.048 \\
Commercial use & -0.062 & 0.073 \\
Public use & 0.012 & 0.084 \\
Joint action & -0.060 & 0.084 \\
Listed & 0.160 & 0.075 \\
Private enterprise & 0.018 & 0.073 \\
Constant & 7.705 & 0.288 \\
Number of obs & 198 & \\
Adj. R-squared & 0.65 & \\
\hline
\end{tabular}

Dependent variable is $\log$ land price. We also include dummy variables for the year of land transaction. Their coefficients are significant, but they are excluded in the table for simplicity

sample are restricted to residential development as the main land use purpose. However, some are allowed/required to have public use or commercial use too. Public and commercial land will, on the one hand, improve the convenience in the neighbourhood which has positive effect on future house prices. On the other hand, they also drive up construction costs. These considerations are taken into account by the developers when they purchase the land parcel. We also include floor area rather than land area in the regression to represent lot size. In China, the maximum floor area ratio is always explicitly provided in any land-leasing contract and developers cannot construct over the floor area stated in the contract. Thus, floor area is more informative than land area in showing the potential of the land parcel.

As for developer characteristics, we use a dummy variable to indicate private ownership, as SOEs normally have stronger financial capability and flexibility to offer high land prices. Another important variable is a dummy variable for joint auction. When two or more developers purchase land parcels jointly, they have improved purchasing power so that they can bid high for favorable land parcels. Therefore, joint auction is a possible signal for high land price.

Table 7 exhibits the estimates of Eq. (9). The models passed all standard diagnostic tests except the VIF (variance inflation factor) test for multicollinearity. The five distance variables are correlated. Multicollinearity leads to inflated standard errors and insignificant $p$-values. However, given that this issue will not affect prediction, which is our main purpose of this analysis, we do not take further action to address this issue.

Funding We are grateful for the financial support from the Economic and Social Research Council (Grant No. ES/P004296/1), the National Natural Science Foundation of China (Grant No. 71661137009), the Department of Land Economy Research Development Fund, and the Senior Members' Research Grant from Newnham College, University of Cambridge. 
Availability of data and material The datasets generated during and analysed during the current study are not publicly available but are available from the corresponding author on reasonable request.

\section{Compliance with ethical standards}

Conflicts of interest The authors declare that they have no conflict of interest.

Open Access This article is licensed under a Creative Commons Attribution 4.0 International License, which permits use, sharing, adaptation, distribution and reproduction in any medium or format, as long as you give appropriate credit to the original author(s) and the source, provide a link to the Creative Commons licence, and indicate if changes were made. The images or other third party material in this article are included in the article's Creative Commons licence, unless indicated otherwise in a credit line to the material. If material is not included in the article's Creative Commons licence and your intended use is not permitted by statutory regulation or exceeds the permitted use, you will need to obtain permission directly from the copyright holder. To view a copy of this licence, visit http://creativecommons.org/licenses/by/4.0/.

\section{References}

Allen, E. J., Dechow, P. M., Pope, D. G., \& Wu, G. (2017). Reference-dependent preferences: Evidence from marathon runners. Management Science, 63, 1657-1672.

Anenberg, E. (2011). Loss aversion, equity constraints and seller behavior in the real estate market. Regional Science and Urban Economics, 41, 67-76.

Arkes, H. R., \& Ayton, P. (1999). The sunk cost and Concorde effects: Are humans less rational than lower animals? Psychological Bulletin, 125, 591-600.

Arkes, H. R., \& Blumer, C. (1985). The psychology of sunk cost. Organizational Behavior and Human Decision Processes, 35, 124-140.

Bao, H. X. H., \& Gong, C. M. (2016). Endowment effect and housing decisions. International Journal of Strategic Property Management, 20, 341-353.

Barberis, N. (2013). Thirty years of prospect theory in economics: A review and assessment. Journal of Economic Perspectives, 27, 173-195.

Barberis, N., \& Huang, M. (2001). Mental accounting, loss aversion, and individual stock returns. Journal of Finance, 56, 1247-1292.

Barberis, N., Huang, M., \& Santos, T. (2001). Prospect theory and asset prices. Quarterly Journal of Economics, 116, 1-53.

Barberis, N., \& Xiong, W. (2009). What drives the disposition effect? An analysis of a long-standing preference-based explanation. Journal of Finance, 64, 751-784.

Beck, T., Demirguc-Kunt, A., Laeven, L., \& Maksimovic, V. (2006). The determinants of financing obstacles. Journal of International Money and Finance, 25, 932-952.

Benartzi, S., \& Thaler, R. H. (1995). Myopic loss aversion and the equity premium puzzle. Quarterly Journal of Economics, 110, 73-92.

Bokhari, S., \& Geltner, D. (2011). Loss aversion and anchoring in commercial real estate pricing: empirical evidence and price index implications. Real Estate Economics, 39, 635-670.

Bourassa, S. C., Hoesli, M., Scognamiglio, D., \& Zhang, S. M. (2011). Land leverage and house prices. Regional Science and Urban Economics, 41, 134-144.

Boycko, M., Shleifer, A., \& Vishny, R. W. (1996). A theory of privatisation. Economic Journal, 106, 309-319.

Bronnenberg, B. J., \& Wathieu, L. (1996). Asymmetric promotion effects and brand positioning. Marketing Science, 15, 379-394.

Charness, G., \& Sutter, M. (2012). Groups make better self-interested decisions. Journal of Economic Perspectives, 26, 157-176.

Colwell, P. F., \& Munneke, H. J. (1997). The structure of urban land prices. Journal of Urban Economics, 41, 321-336.

Cooper, D. J., \& Kagel, J. H. (2005). Are two heads better than one? Team versus individual play in signaling games. American Economic Review, 95, 477-509.

Dai, T. T., Jiang, S. Y., Sun, A., \& Wu, S. H. (2020). Inequality and social capital: How inequality in china's housing assets affects people's trust. Emerging Markets Finance and Trade, 56, 562-575. 
DellaVigna, S. (2009). Psychology and economics: Evidence from the field. Journal of Economic Literature, 47, 315-372.

Deng, Y., Gyourko, J., \& Wu, J. (2012). Land and house price measurement in China. National Bureau of Economic Research Working Paper Series, No. 18403.

Diao, X. S., Zhang, Y. M., \& Chen, K. Z. (2012). The global recession and China's stimulus package: A general equilibrium assessment of country level impacts. China Economic Review, 23, 1-17.

Ding, C. R., \& Zhao, X. S. (2014). Land market, land development and urban spatial structure in Beijing. Land Use Policy, 40, 83-90.

Dombrow, J., Knight, J. R., \& Sirmans, C. F. (1997). Aggregation bias in repeat-sales indices. Journal of Real Estate Finance and Economics, 14, 75-88.

Du, J. F., \& Peiser, R. B. (2014). Land supply, pricing and local governments' land hoarding in China. Regional Science and Urban Economics, 48, 180-189.

Engelhardt, G. V. (2003). Nominal loss aversion, housing equity constraints, and household mobility: Evidence from the United States. Journal of Urban Economics, 53, 171-195.

Fekrazad, A. (2019). Earthquake-risk salience and housing prices: Evidence from California. Journal of Behavioral and Experimental Economics, 78, 104-113.

Follain, J. R., \& Jimenez, E. (1985). Estimating the demand for housing characteristics: A survey and critique. Regional Science and Urban Economics, 15, 77-107.

Gao, X. L., \& Asami, Y. (2007). Influence of lot size and shape on redevelopment projects. Land Use Policy, 24, 212-222.

Genesove, D., \& Mayer, C. (2001). Loss aversion and seller behavior: Evidence from the housing market. Quarterly Journal of Economics, 116, 1233-1260.

Geoghegan, J., Wainger, L. A., \& Bockstael, N. E. (1997). Spatial landscape indices in a hedonic framework: An ecological economics analysis using GIS. Ecological Economics, 23, 251-264.

Glaeser, E., Huang, W., Ma, Y. R., \& Shleifer, A. (2017). A Real estate boom with Chinese characteristics. Journal of Economic Perspectives, 31, 93-116.

Glode, V., Hollifield, B., Kacperczyk, M., \& Kogan, S. (2009). Is investor rationality time varying? Evidence from the mutual fund industry. National Bureau of Economic Research Working Paper Series, No. 15038.

Halvorsen, R., \& Pollakowski, H. O. (1981). Choice of functional form for hedonic price equations'. Journal of Urban Economics, 10, 37-49.

Hamnett, C. (2020). Is Chinese urbanisation unique? Urban Studies, 57, 690-700.

Hardie, B. G. S., Johnson, E. J., \& Fader, P. S. (1993). Modeling loss aversion and reference dependence effects on brand choice. Marketing Science, 12, 378-394.

He, C. F., Zhou, Y., \& Huang, Z. J. (2016). Fiscal decentralization, political centralization, and land urbanization in China. Urban Geography, 37, 436-457.

Hyun, D., \& Milcheva, S. (2018). Spatial dependence in apartment transaction prices during boom and bust. Regional Science and Urban Economics, 68, 36-45.

Hyun, D., \& Milcheva, S. (2019). Spatio-temporal effects of an urban development announcement and its cancellation on house prices: A quasi-natural experiment. Journal of Housing Economics, 43, 23-36.

Kahneman, D., \& Tversky, A. (1979). Prospect theory: An analysis of decision under risk. Econometrica, 47, 263-291.

Kleven, H. J., \& Waseem, M. (2013). Using notches to uncover optimization frictions and structural elasticities: Theory and evidence from Pakistan. Quarterly Journal of Economics, 128, 669-723.

Kok, N., Monkkonen, P., \& Quigley, J. M. (2014). Land use regulations and the value of land and housing: An intra-metropolitan analysis. Journal of Urban Economics, 81, 136-148.

Kornai, J., Maskin, E., \& Roland, G. (2003). Understanding the soft budget constraint. Journal of Economic Literature, 41, 1095-1136.

Krueger, A. O. (1990). Government failures in development. Journal of Economic Perspectives, 4, 9-23.

Leung, T. C., \& Tsang, K. P. (2013). Anchoring and loss aversion in the housing market: Implications on price dynamics. China Economic Review, 24, 42-54.

Liang, C. M., Lee, C. C., \& Yong, L. R. (2020). Impacts of urban renewal on neighborhood housing prices: Predicting response to psychological effects. Journal of Housing and the Built Environment, $35,191-213$.

Liu, Y., Gallimore, P., \& Wiley, J. A. (2015). Nonlocal office investors: Anchored by their markets and impaired by their distance. Journal of Real Estate Finance and Economics, 50, 129-149.

Maclennan, D., \& O'Sullivan, A. (2011). The global financial crisis: Challenges for housing research and policies. Journal of Housing and the Built Environment, 26, 375-384. 
McKissack, A., \& Xu, J. Y. (2011). Chinese macroeconomic management through the crisis and beyond. Asian-Pacific Economic Literature, 25, 43-55.

Odean, T. (1998). Are investors reluctant to realize their losses? Journal of Finance, 53, 1775-1798.

Ong, S. E., Neo, P. H., \& Tu, Y. (2008). Foreclosure sales: The effects of price expectations, volatility and equity losses. Journal of Real Estate Finance and Economics, 36, 265-287.

Ong, S. E., Sing, T. F., \& Teo, A. H. L. (2007). Delinquency and default in arms: The effects of protected equity and loss aversion. Journal of Real Estate Finance and Economics, 35, 253-280.

Pagano, M., Panetta, F., \& Zingales, L. (1998). Why do companies go public? An empirical analysis. Journal of Finance, 53, 27-64.

Polloni, S. (2019). Traffic calming and neighborhood livability: Evidence from housing prices in Portland. Regional Science and Urban Economics, 74, 18-37.

Pope, D. G., \& Schweitzer, M. E. (2011). Is tiger woods loss averse? Persistent bias in the face of experience, competition, and high stakes. American Economic Review, 101, 129-157.

Putler, D. S. (1992). Incorporating reference price effects into a theory of consumer choice. Marketing Science, 11, 287-309.

Qu, S. J., Hu, S. G., Li, W. D., Zhang, C. R., Li, Q. F., \& Wang, H. (2020). Temporal variation in the effects of impact factors on residential land prices. Applied Geography, 114, 102124.

Ray, D., Shum, M., \& Camerer, C. F. (2015). Loss aversion in post-sale purchases of consumer products and their substitutes. American Economic Review, 105, 376-380.

Rosen, S. (1974). Hedonic prices and implicit markets: Product differentiation in pure competition. Journal of Political Economy, 82, 34-55.

Schoubben, F., \& Van Hulle, C. (2011). Stock listing and financial flexibility. Journal of Business Research, 64, 483-489.

Shefrin, H., \& Statman, M. (1985). The disposition to sell winners too early and ride losers too long: Theory and evidence. Journal of Finance, 40, 777-790.

Sirmans, G. S., Macpherson, D. A., \& Zietz, E. N. (2005). The composition of hedonic pricing models. Journal of Real Estate Literature, 13, 3-43.

Stein, J. C. (1995). Prices and trading volume in the housing market: A model with down-payment effects. Quarterly Journal of Economics, 110, 379-406.

Thaler, R. H. (1985). Mental accounting and consumer choice. Marketing Science, 4, 199-214.

Thaler, R. H., \& Johnson, E. J. (1990). Gambling with the house money and trying to break even: The effects of prior outcomes on risky choice. Management Science, 36, 643-660.

Tse, R. Y. C. (2002). Estimating neighbourhood effects in house prices: Towards a new hedonic model approach. Urban Studies, 39, 1165-1180.

Tversky, A., \& Kahneman, D. (1992). Advances in prospect theory: Cumulative representation of uncertainty. Journal of Risk and Uncertainty, 5, 297-323.

Wang, X. Q., Hao, L. N., Tao, R., \& Su, C. W. (2020). Does money supply growth drive housing boom in China? A wavelet-based analysis. Journal of Housing and the Built Environment, 35, 125-141.

Wang, Z., \& Zhang, Q. H. (2014). Fundamental factors in the housing markets of China. Journal of Housing Economics, 25, 53-61.

Wen, H. Z., Chu, L. H., Zhang, J. F., \& Xiao, Y. (2018). Competitive intensity developer expectation and land price: Evidence from Hangzhou China. Journal of Urban Planning and Development, 144, 04018040.

Yang, Z., Ren, R. R., Liu, H. Y., \& Zhang, H. (2015). Land leasing and local government behaviour in China: Evidence from Beijing. Urban Studies, 52, 841-856.

Publisher's Note Springer Nature remains neutral with regard to jurisdictional claims in published maps and institutional affiliations. 